\title{
PALEO
}

Revue d'archéologie préhistorique

$22 \mid 2011$

Varia

\section{La pointe des Vachons}

Nouvelles approches d'un fossile directeur controversé du Gravettien à partir des exemplaires du niveau IV de la grotte d'Isturitz (PyrénéesAtlantiques, France) et des niveaux 4 des abris 1 et 2 des Vachons (Charente, France)

The Vachons point: new approach to a gravettian controversial « fossile directeur " from the specimens of level IV from Isturitz cave (PyrénéesAtlantiques, France) and of levels 4 from shelters 1 and 2 of les Vachons (Charente, France)

\section{Aurélien Simonet}

\section{OpenEdition}

\section{Journals}

Édition électronique

URL : http://journals.openedition.org/paleo/2159

DOI : $10.4000 /$ paleo.2159

ISSN : 2101-0420

Éditeur

SAMRA

\section{Édition imprimée}

Date de publication : 1 décembre 2011

ISSN : 1145-3370

Référence électronique

Aurélien Simonet, "La pointe des Vachons », PALEO [En ligne], 22 | 2011, mis en ligne le 19 avril 2012, consulté le 07 juillet 2020. URL : http://journals.openedition.org/paleo/2159 ; DOl : https://doi.org/ 10.4000/paleo.2159

\section{cc) (†)}

PALEO est mis à disposition selon les termes de la licence Creative Commons Attribution - Pas d'Utilisation Commerciale - Pas de Modification 4.0 International. 


\title{
LA POINTE DES VACHONS : nouvelles approches d'un fossile directeur controversé du Gravettien à partir des exemplaires du niveau IV de la grotte d'Isturitz (Pyrénées-Atlantiques, France) et des niveaux 4 des abris 1 et 2 des Vachons (Charente, France)
}

\author{
Aurélien SIMONET ${ }^{(1)}$
}

\begin{abstract}
Résumé : L'étude de l'ensemble des pointes à dos gravettiennes du niveau IV de la grotte d'Isturitz (PyrénéesAtlantiques, France) et des niveaux 4 des abris 1 et 2 des Vachons (Charente, France) permet de reconnaitre une unité remarquable au-delà de la seule prise en compte de la présence de retouche inverse rasante qui différenciait jusqu'à présent les pointes des Vachons des pointes de la Gravette. Nous proposons ainsi d'identifier comme " pointes des Vachons » l'ensemble des pointes à dos du niveau IV d'Isturitz et des niveaux 4 des abris 1 et 2 des Vachons car, quelles que soient les techniques de façonnage employées, elles répondent toutes à un modèle qui correspondrait à une recherche de symétrie axiale, d'épaisseur et d'étroitesse. À l'aide d'un examen de la littérature scientifique associé à une première révision de certains assemblages (Laussel, Brassempouy, Pataud, Pair-Non-Pair, Roc de Gavaudun, grotte de l'Observatoire), nous proposons l'hypothèse selon laquelle l'emploi d'une retouche inverse rasante au niveau des extrémités, qui était à l'origine de la création du type (Sonneville-Bordes et Perrot 1956), ne serait plus un critère de différentiation typologique. Ainsi, si toutes les pointes des Vachons ne porteraient pas de retouche inverse rasante, toutes les pointes à dos portant une retouche inverse rasante ne seraient pas des pointes des Vachons. L'ensemble des assemblages archéologiques français au sein desquels cette pièce a pu être reconnue semblent se rapporter au Gravettien moyen à burins de Noailles. Notre objectif est de proposer un premier jalon vers une réévaluation de l'ensemble des pointes à dos gravettiennes qui permettra de progresser sur la compréhension chrono-stratigraphique du Gravettien. En effet, ne serait-il pas possible d'identifier différents types de pointes à dos au sein de l'ensemble générique des pointes de la Gravette?
\end{abstract}

Mots-clés : pointe des Vachons, Isturitz, Les Vachons, typologie lithique, Gravettien à burins de Noailles.

Key-words: Vachons point, Isturitz, Les Vachons, lithic typology, Middle Gravettian with Noailles burins.

Abridged english version

The Vachons point: new approach to a Gravettian controversial «fossile directeur » from the specimens of level IV from Isturitz cave (Pyrénées-Atlantiques, France) and of levels 4 from shelters 1 and 2 of Les Vachons (Charente, France).

Introduction

Recognized at the beginning of the 20th century, Vachons points are backed points characterized by the presence of a low angle inverse retouch in one or both extremities (Sonneville-Bordes and Perrot 1956). The study of two important gravettian assemblages of backed points (Isturitz IV and Les Vachons, shelters 1 and 2, levels 4) shows a conceptual unity beyond the presence of a low angle inverse retouch. Our objective is to take the first steps toward a reevaluation of the whole gravettian backed points in order to increase the understanding of the gravettian chrono-stratigraphy. Would not be possible to identify different types of backed points in the generic type of Gravette point? 


\section{1 - Old definition and problematic}

Vachons point forms a distinct group in the traditional typology, the number 50 of Sonneville-Bordes and Perrot's list. "N 50 - Vachons point: variant of Gravette point, carrying a low angle inverse retouch at the basal and apical extremities" (SonnevilleBordes and Perrot 1956 p. 547 and fig. 1). Nevertheless, many researchers deny this differentiation, thus continuing the thought of François Bordes : Vachons points just would be technical improved Gravette point (Bordes 1965). On the other hand, Cheynier, from the years 1960, had understood the importance of Vachons point as a fossile directeur for the french Middle Gravettian. It can be noticed that the illustration of this fossile directeur he proposed has a striking typological identity with the specimens from Isturitz we propose to describe (Cheynier 1965). The point, with a perfect symmetry and without low angle inverse retouch, is associated with a posterior phase of La Gravette (fig. $1-n^{\circ} 2$ ). But Cheynier had not formalized particular criterion to identify Vachons point. In this research perspective, would it be possible to refine the definition of this type ?

\section{2 - Toward a new definition}

\section{1 - Data from the level IV of Isturitz (Pyrénées-Atlantiques, France)}

Our study of the whole level IV backed points from Isturitz enabled us to recognize a remarkable unity in spite of the presence or the absence of a low angle inverse retouch (fig. 2, 3, 4). We thus propose to identify as "Vachons points « all gravettian backed points from the level IV of Isturitz $(\mathrm{N}=269)$ because, whatever the techniques of shaping employed, they all answer a standard shape which would correspond to a search for axial symmetry, thickness and narrowness (tabl. 1).

The lengths of the intact backed points vary between 35 and $96,5 \mathrm{~mm}$ with two peaks between 50 and $55 \mathrm{~mm}$ on the one hand and between 70 and $75 \mathrm{~mm}$ on the other hand (fig. 5). The width, the thickness and the weight of backed points follow a unimodal distribution with, respectively, a concentration between 8 and $9 \mathrm{~mm}$ for the width (with an average and a median of $10 \mathrm{~mm}$ ), between 4 and $5 \mathrm{~mm}$ for the thickness (with an average and a median of $5 \mathrm{~mm}$ ), and between 1 and $4 \mathrm{~g}$ for the weight (with an average to $2,9 \mathrm{~g}$ and a median to $2,5 \mathrm{~g}$ ) (fig. 5). The back of the 99 intact points is as well lateralized on the right side $(\mathrm{N}=45)$ as on the left side $(\mathrm{N}=44)$.

The study of gravettian backed points from Isturitz shows that the use of a low angle inverse retouch is a method that mainly ensures the correction of the morphology of the extremities (fig. 6). Other potential methods are nevertheless possible like the use of a direct retouch. More than the presence of a low angle inverse retouch, it is the elegance of these points with a narrow and symmetrical morphology which is an extremely powerful unifying criterion. Beyond the variability of their size, backed points from level IV have a great conceptual homogeneity (fig. 2, 3, 4). The deviant cases are rare and clearly show the underlying failed concept (fig. 9). Definitely, the required concept is a thick, narrow and lanceolate point. The low angle inverse retouch is a particularly meticulous way to obtain this result.

The significant proportion of complex fractures in Isturitz (33\%) confirms the majority use of Vachons points as projectile point (fig. 7). On the other hand, a few specimens whose curved laminar blank contradicts a use as projectile point take part in the argumentation of a functional distinction (knife/projectile) within the same typological group (fig. $4-\mathrm{n}^{\circ} 1$ ).

The laminar blanks of Vachons points are extracted from curved cores with one or two striking platforms (fig. 8). The principle of auto-maintenance with an alternation of series of laminar blanks extracted from secant flaked surfaces is a great principle of the gravettian "debitage" from Isturitz.

\section{2 - Data from levels 4 of Les Vachons, shelters 1 and 2 (Charente, France)}

In each of the two small adjoining shelters of Les Vachons (shelters 1 and 2), backed points have identical templates (fig. 10 , 11, 12 et tabl. 2). Their general morphology respects a search for symmetry but their base is very often made by convex oblique truncation. The back is mainly made by direct retouch while the delineation of the edge opposed to the back is very often corrected over its bigger length using a direct retouch. The back is mainly made on the left side. A low angle inverse retouch is very often used in the morphological correction of the extremities. In each of the two shelters, the complex fractures indicating the use of a part at least of the points as projectile are rare (absent in Shelter 1, 3 indications in Shelter 2).

Concerning backed points, the only difference between shelter 1 and shelter 2 is the morphology of the base of the points which is more generally sharpened in shelter 1 and rounded in shelter 2 . This difference could result from the low sample of the points from shelter 1 . So it seems relevant to correlate the assemblages from levels 4 of the two shelters within the same chronoculturel unit although we are not able to affirm their contemporaneity.

\section{3 - Isturitz and Les Vachons : unity and variability of backed points}

Backed points from Les Vachons, shelter 1 and 2, are very similar to the ones from Isturitz, level IV. First, symmetry in relation to the longitudinal axis is a mutual criterion. Moreover, the width/thickness ratio of the majority of backed points from both sites is about $10 \mathrm{~mm}$ for $5 \mathrm{~mm}$ (fig. 13). It is possible to infer from their morphometric characteristics that these points may have a similar axial hafting with a mortise about $5 \mathrm{~mm}$ width (fig. 14). 


\section{3 - Synthesis and research perspectives}

In spite of a margin of morphological variability whose interpretation remains to be developed (influence of raw material?), we can already propose the existence of general common characteristics (fig. 14, 15 and tabl. 3). The new definition of Vachons point would be the following one:

«Backed point narrow, thick and symmetrical. The axis of symmetry corresponds to the longitudinal axis uniting the two extremities. The delineation of the back is convex in an effect of symmetry with the opposed edge. The shape of the point is clearly lanceolate since the maximum width does not correspond to the middle of the height but more generally to the lower third. The back is thick and total. The edge opposed to the back is often regularized by direct retouch in particular in the extremities in order to refine symmetry. Lastly, a particular care is often expressed during the finishing of the object (sharpened of extremities) by the possible use of a low angle inverse retouch. "

At the present time, Vachons points seem to be associated with the Middle Gravettian with Noailles burins (fig. 16, 17, 18) but the majority of the archeological assemblages comes from old excavations. In future, our objective is to demonstrate that Vachons points would come after the twisted and marginal backed points from lower Gravettian (Pesesse, 2006, 2008) and would be replaced in recent Gravettian from south-west France with very straight backed points as in the recent Gravettian of Abri Pataud (Bricker dir. 1995), Cirque de la Patrie (Klaric 2003) or Tercis (Thibault 1970 ; Simonet 2009) or with angular backed points as in the recent Gravettian of Corbiac (Kozlowski et Lenoir 1988) (fig. 19). Moreover, in south-east France and in Italy, Vachons point could also endure in technocomplexes which come after the Gravettian as in the Proto-Arenian and Epigravettian (fig. 20).

\section{Introduction}

Alors que la Préhistoire connaît une phase de caractérisation technologique d'outils anciennement définis, il reste encore d'anciens types dont la définition très large doit être remise à jour d'un point de vue typologique au sens strict. C'est le cas de la pointe des Vachons qui fait l'objet de cet article. La dénomination «Vachons » a été appliquée aux pointes à dos qui portent une retouche inverse rasante à l'une ou aux deux extrémités (Sonneville-Bordes et Perrot 1956). Cette définition confère à ces pointes à dos un rôle très faible comme fossile directeur étant donné que les pointes à dos et a fortiori les pointes à dos à retouche inverse rasante, à partir de leur invention par les gravettiens, connurent un succès quasiment permanent au sein des sociétés préhistoriques. Dans la typologie de l'industrie lithique du Paléolithique supérieur, il s'agit ainsi de l'un des types dont la définition est la plus floue. Dans l'attente d'une réévaluation globale des assemblages de pointes à dos gravettiennes, cet article propose d'apporter de nouveaux indices en faveur de l'individualisation de ce type de pointe à dos à partir de l'étude comparée des exemplaires du niveau IV de la grotte d'Isturitz (collection Saint-Périer, musée d'Archéologie nationale) et des niveaux 4 des abris 1 et 2 des Vachons (collection Coiffard, musée national de Préhistoire). Cette étude sera confrontée aux données publiées dans l'objectif de proposer une discussion autour de la nature et de la signification archéologique de cette armature à dos.

\section{1 - Ancienne définition et problématique}

La pointe des Vachons forme un groupe distinct dans la typologie classique, le $n^{\circ} 50$ de la liste de D. de SonnevilleBordes et J. Perrot. « $n^{\circ} 50$ - pointe des Vachons : variante de la pointe de la Gravette, portant des retouches plates sur la face plane aux extrémités distale et proximale » (Sonneville-Bordes et Perrot 1956 - p. 547) ; (fig.1 - $\mathrm{n}^{\circ} 1$ ).

La nécessité d'individualiser cette pointe à dos de l'ensemble générique a dès lors été beaucoup critiquée. S'inscrivant dans la continuité de la pensée de François Bordes, de nombreux chercheurs ne retiennent pas cette différenciation. « Pour le moment, la pointe de la Gravette, la microgravette et la gravette atypique semblent suffire. La " pointe des Vachons » (...) est une erreur, un legs du passé, qui disparaîtra » (Bordes 1965 - p. 373). Dans cette démarche, la pointe des Vachons ne serait qu'une pointe de la Gravette techniquement « améliorée » comme l'avait déjà annoncé Heinzelin de Braucourt (Heinzelin de Braucourt 1962 - p. 33).

Jusqu'à présent, seules les recherches de Cheynier offrent une autre perspective. Doté d'une solide connaissance du matériel lithique gravettien, Cheynier avait amorcé sa propre structuration du Gravettien en marge des considérations officielles. Sa modernité remarquable s'exprimait notamment dans l'acceptation d'une structuration modulable et la prise en compte de l'importance des armatures dans la compréhension du phénomène gravettien (Cheynier 1965). La pointe des Vachons y trouvait toute sa place, d'abord sous la forme d'un fossile directeur strictement associé au burin de Noailles, plus tardivement comme indicateur d'un faciès à part entière, le " moment à pointes des Vachons " (Cheynier 1965). L'illustration de ce fossile directeur présente une pointe, de symétrie parfaite et sans retouche inverse rasante des extrémités, qui possède une identité morphologique remarquable avec les exemplaires de la grotte d'Isturitz que nous décrivons par la suite (Cheynier 1965) ; (fig. 1 - n²). Néanmoins, Cheynier n’a pas formalisé les critères qui lui paraissaient pertinents pour individualiser une pointe des Vachons. Par ailleurs, le rayonnement intellectuel de François Bordes devait 


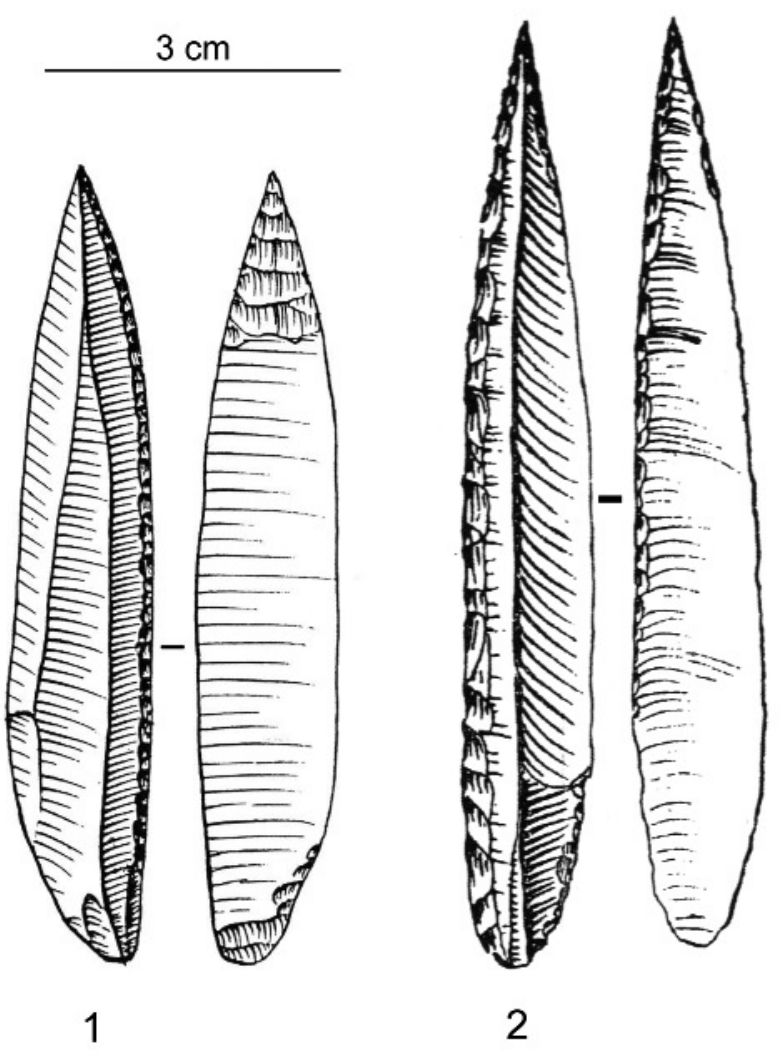

Figure 1 - Pointes des Vachons. $N^{\circ} 1$ : illustration de la définition de Sonneville-Bordes et Perrot, 1956. Les Vachons, abri 1, niveau 4. D'après Bouyssonie, 1948, fig. 9. $N^{\circ} 2$ : modèle-type de pointe des Vachons caractérisant un « moment » du Gravettien selon Cheynier. D'après Cheynier 1965, fig. 9.

Figure 1 - Vachons point. $N^{\circ} 1$ : illustration of the definition from Sonneville-Bordes' and Perrot's typology, 1956. Les Vachons, shelter 1, level 4. After Bouyssonie, 1948, fig. 9. N²: example of Vachons point characteristic of a gravettian " moment » according to Cheynier. After Cheynier 1965, fig. 9.

repousser à plus tard l'ultime aboutissement de ces recherches précises, richement illustrées et passionnantes. Quarante années ont passé durant lesquelles la pointe des Vachons a été écartée des chronologies d'attente successives.

Car, parmi les grandes cultures du Paléolithique supérieur, le Gravettien est peut-être celle dont la structuration chrono-culturelle est la plus complexe (Delporte 1983 ; Rigaud 1982 ; Bosselin et Djindjian 1994a et b ; Klaric 2003). Pour progresser sur cette question, il est donc d'autant plus important d'affiner la typologie lithique. La richesse des différents types d'armatures, notamment, est encore loin d'être décrite d'une manière exhaustive. Si de nouveaux types peuvent encore être individualisés à l'instar des recherches actuelles sur la lamelle de la Picardie (Klaric et al. 2002) ou la pointe à dos alterne (Pesesse 2006), d'anciens types méconnus comme la pointe de Tursac (Pesesse 2008) ou la pointe des Vachons
(Simonet 2009) méritent d'être réévalués avec les outils d'analyse modernes. Cet article représente un premier jalon, nécessairement limité, vers cette perspective de recherche.

\section{2 - Vers une nouvelle définition}

\section{1 - Les données du niveau IV d'Isturitz (Pyrénées-Atlantiques, France)}

\subsection{1 - La séquence archéologique, critique et évaluation}

Deux grandes campagnes de fouilles ont été menées dans la grotte d'Isturitz : celles d'E. Passemard se sont déroulées de 1912 à 1923 (Passemard 1944) suivies par celles du Comte et de la Comtesse René et Suzanne de Saint-Périer entre 1928 et 1952 (Saint-Périer 1952). Deux niveaux gravettiens ont été reconnus dans chacune des deux campagnes de fouilles. Le niveau supérieur est beaucoup moins dense et semble, d'autre part, souffrir davantage de mélanges comme l'illustrent les raccords récents de fragments de pointes osseuses avec d'autres fragments issus du niveau solutréen (Goutas 2004). Nous nous concentrerons donc sur le niveau inférieur à la fois plus riche et moins sujet aux mélanges ainsi que sur la collection plus abondante des Saint-Périer (niveau IV).

\subsection{2 - Présentation de l'industrie du niveau IV, critique et évaluation de son homogénéité}

\subsubsection{1 - Présentation des pointes à dos}

Le niveau IV comprend la plus grande collection de pointe à dos rapportées au Gravettien à burins de Noailles avec 269 exemplaires (tabl. 1). Le grand nombre de pièces entières (99 exemplaires) se prête à une analyse morphologique. Un premier aperçu sur ces pointes à dos montre une grande unité morphotechnique malgré la diversité des modalités de retouche (fig. 2,3 et 4). II s'ensuit que nous utiliserons une dénomination unique " pointe des Vachons " pour l'ensemble des pointes à dos, terminologie d'attente qui sera testée dans un premier temps à partir de l'étude des exemplaires de la grotte d'Isturitz, dans un second temps à l'aide d'une confrontation entre ces données et celles du site éponyme.

\begin{tabular}{|l|r|r|}
\hline & $\mathbf{N}$ & $\mathbf{\%}$ \\
\hline Pointe à dos entière ou presqu'entière & $\mathbf{9 9}$ & $\mathbf{3 7 , 6 0 \%}$ \\
\hline fragment basal & 76 & $28,60 \%$ \\
\hline fragment mésial & 33 & $11,70 \%$ \\
\hline fragment apical & 35 & $12,80 \%$ \\
\hline fragment indéterminé, basal ou apical ? & 26 & $9,40 \%$ \\
\hline Total & $\mathbf{2 6 9}$ & $\mathbf{1 0 0 \%}$ \\
\hline
\end{tabular}

Tableau 1 - Distribution des pointes à dos d'Isturitz. Collection Saint-Périer, niveau IV.

Table 1 - Distribution of backed points from Isturitz. Saint-Périer collection, level IV. 

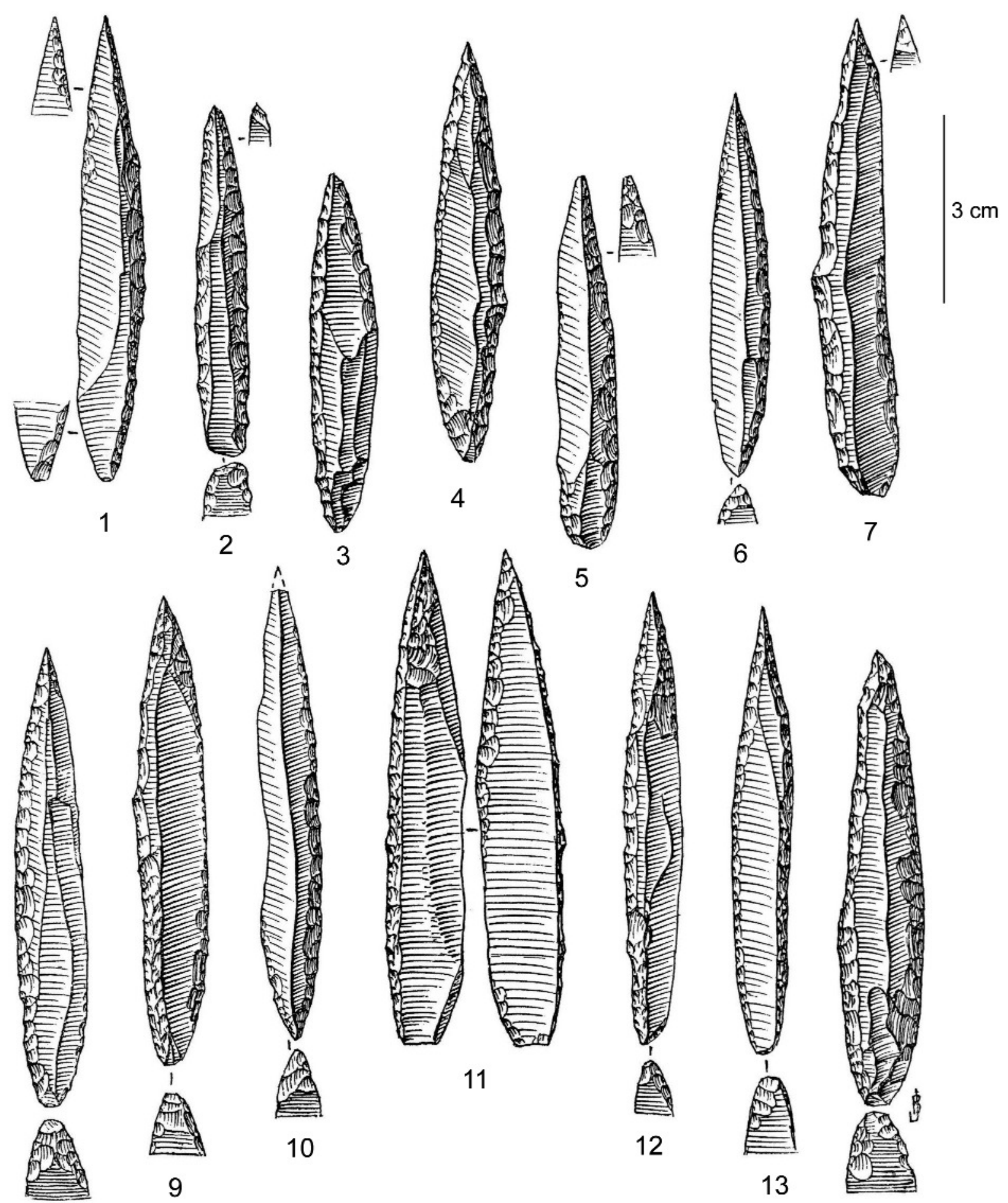

8

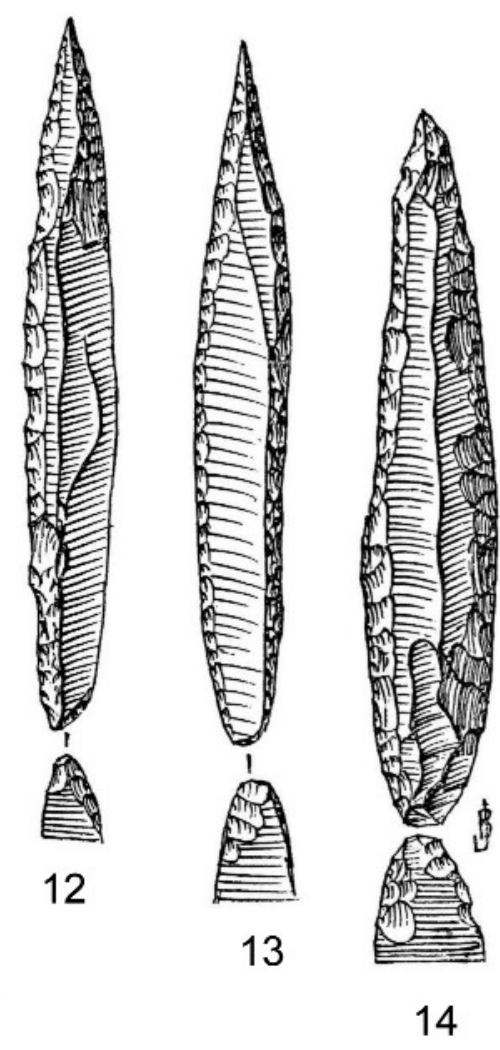

Figure 2 - Pointes des Vachons d'Isturitz, niveau IV. Collection Saint-Périer. M.A.N. D’après Saint-Périer 1952, fig. 42. Figure 2 - Vachons points from Isturitz, level IV. Saint-Périer collection. M.A.N. After Saint-Périer 1952, fig. 42. 


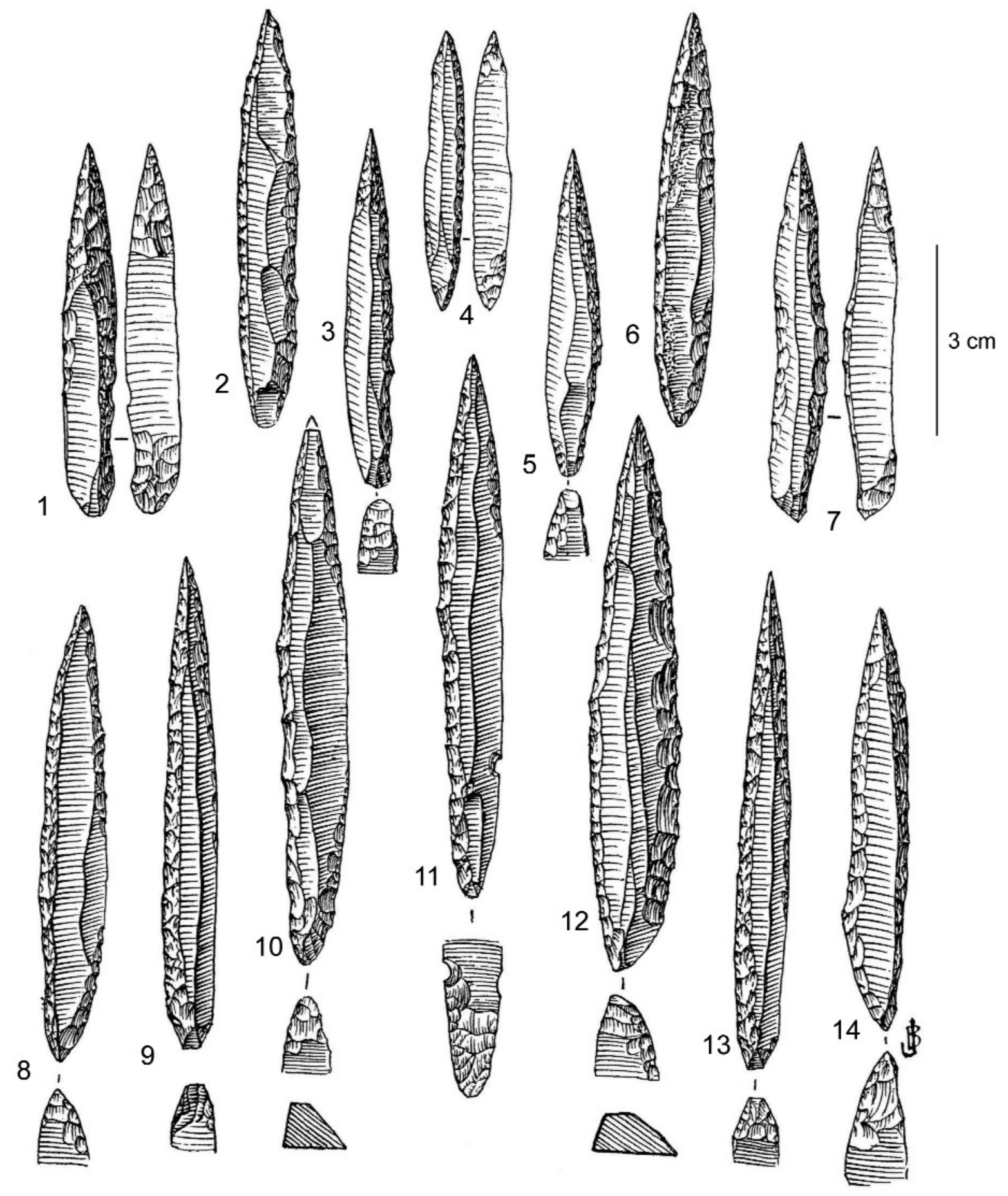

Figure 3 - Pointes des Vachons d'Isturitz, niveau IV. Collection Saint-Périer. M.A.N. D'après Saint-Périer 1952, fig. 43. Figure 3 - Vachons points from Isturitz, level IV. Saint-Périer collection. M.A.N. After Saint-Périer 1952, fig. 43. 


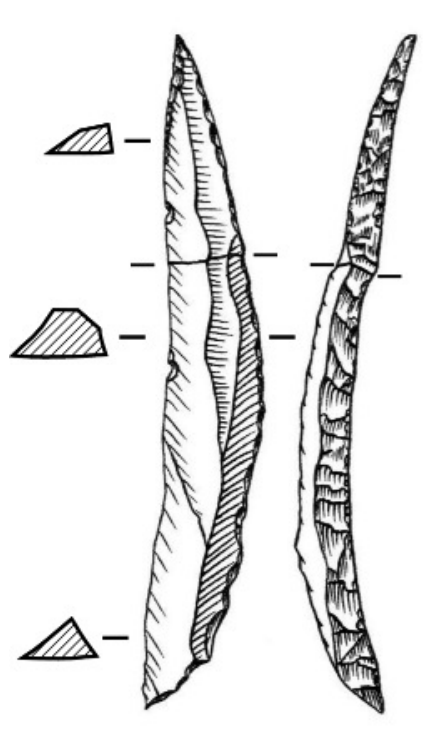

1

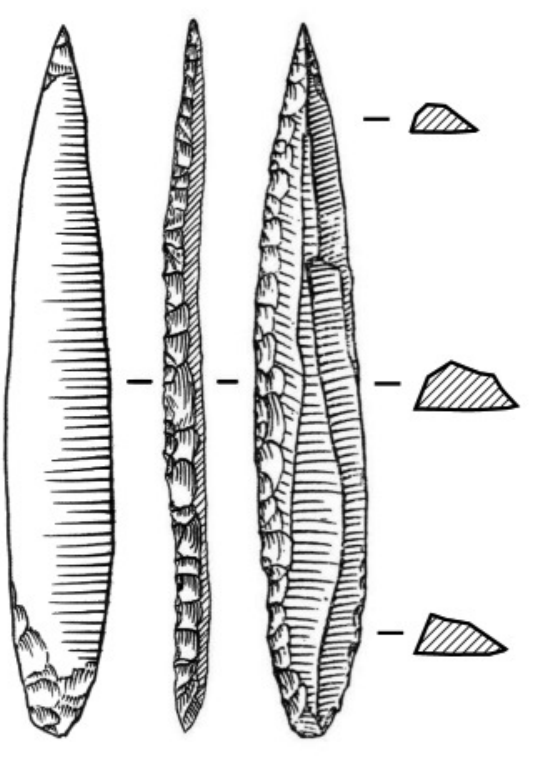

2

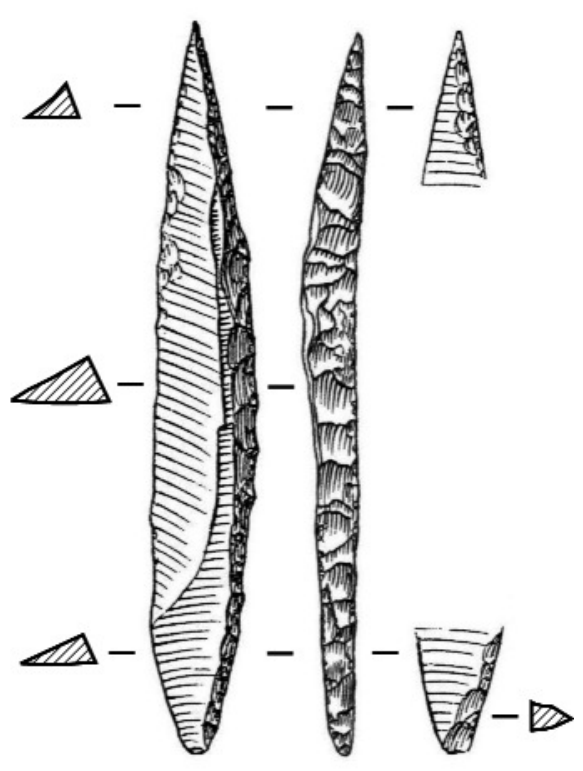

3

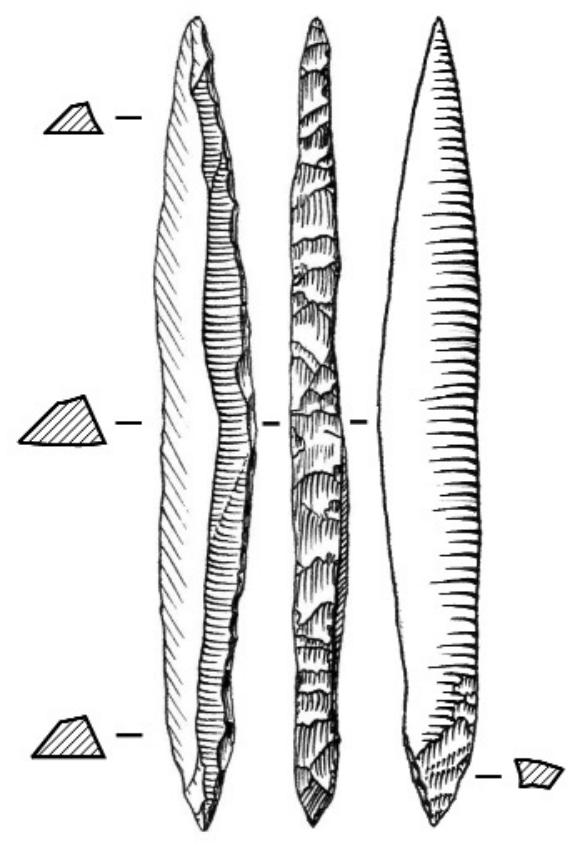

4

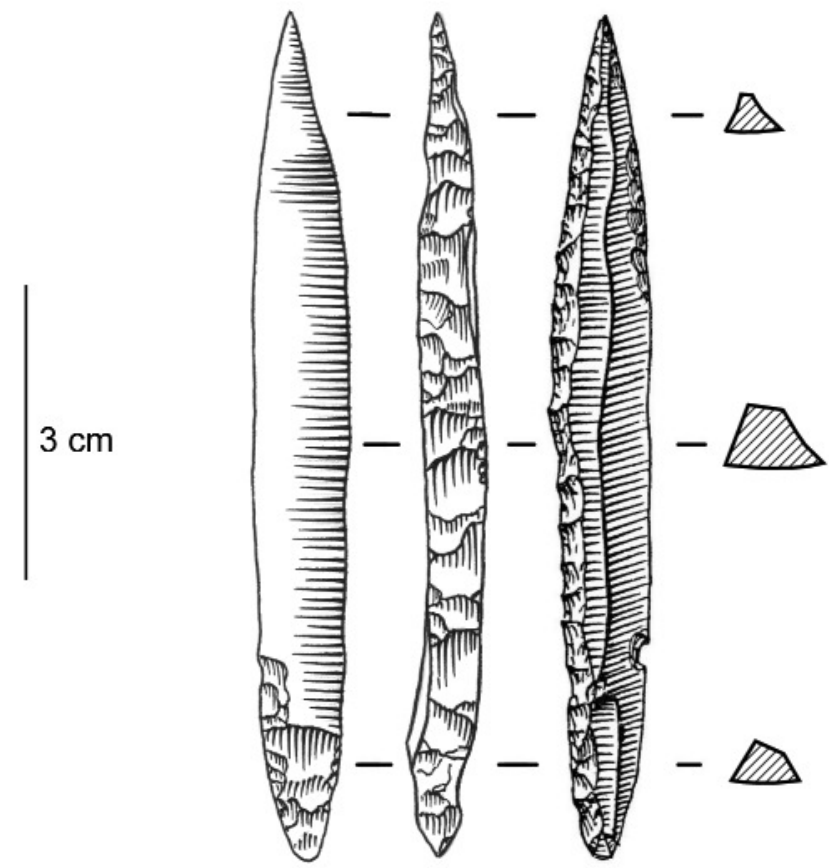

5

Figure 4 - Pointes des Vachons d'Isturitz, niveau IVIF3. No 1 : collection Passemard, niveau F3, M.A.N. Nos 2 à 5 : collection Saint-Périer,

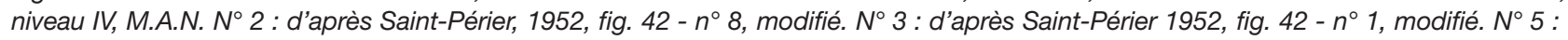
d'après Saint-Périer 1952, fig. 43 - $n^{\circ} 11$, modifié. Nos 1 et 4. Dessins A. Simonet.

Figure 4 - Vachons points from Isturitz, level IV/F3. $N^{\circ} 1$ : Passemard collection, level F3, M.A.N. Nos 2 to 5: Saint-Périer collection,

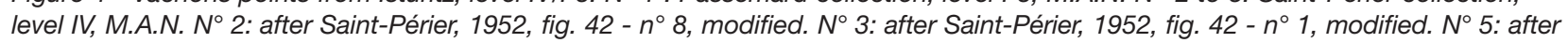
Saint-Périer 1952, fig. $43-n^{\circ} 11$, modified. Nos 1 et 4 . Drawings A. Simonet. 


\subsubsection{2 - Caractères morphotechniques}

Les longueurs des pointes à dos entières sont comprises entre 35 et $96,5 \mathrm{~mm}$ (fig. 5 - $\mathrm{n}^{\circ}$ 1). On observe un continuum dans la distribution des longueurs bien qu'il existe des exemplaires de taille très différente. Nous observons néanmoins deux pics, l'un, plus élevé, entre 70 et $75 \mathrm{~mm}$, l'autre, plus faible, entre 50 et $55 \mathrm{~mm}$ (fig. 5 - $\mathrm{n}^{\circ} 1$ ).

Que représentent les deux gabarits de pointes à dos ? Une intention des tailleurs ou un artifice de nos recherches ? La longueur de la majorité des pointes oscille cependant entre 50 et $60 \mathrm{~mm}$, avec une moyenne et une médiane, respectivement de 59 et de $58 \mathrm{~mm}$. Un gabarit particulier entre 50 et $60 \mathrm{~mm}$ pourrait être recherché avec une marge de manœuvre importante en ce qui concerne la longueur.

La largeur, l'épaisseur et le poids des pointes à dos suivent par contre une distribution unimodale avec, respectivement, une concentration entre 8 et $9 \mathrm{~mm}$ pour la largeur (avec une moyenne et une médiane de $10 \mathrm{~mm}$ ), entre 4 et $5 \mathrm{~mm}$ pour l'épaisseur (avec une moyenne et une médiane de $5 \mathrm{~mm}$ ), et entre 1 et $4 \mathrm{~g}$ pour le poids (avec une moyenne à 2,9 $\mathrm{g}$ et une médiane à 2,5 g) (fig. 5).

\subsubsection{3 - Caractères morphotechniques}

La répartition des pointes à dos selon leur latéralisation est parfaitement équitable. Le dos des pointes est en effet

\section{Effectif}

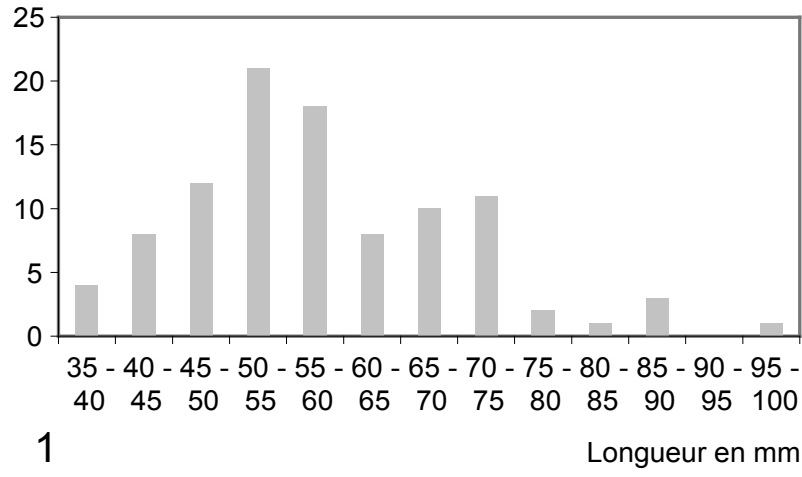

Effectif

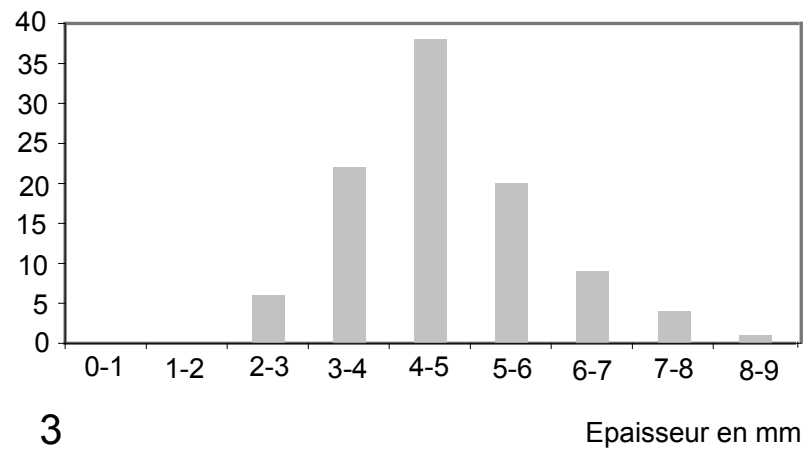

aussi bien dextre que senestre puisque sur 99 pointes entières, 45 sont latéralisées à droite et 44 à gauche. Le dos des pointes est majoritairement aménagé par retouche croisée (70 exemplaires soit $71 \%$ ) mais aussi par retouche directe (29 exemplaires soit $29 \%$ ). Toutefois, la retouche croisée d'une grande partie des dos intervient au niveau de la base et/ou de la partie apicale de la pointe, c'est-à-dire, étant donné la forme très généralement lancéolée, dans la zone ou l'abattement du dos est amené à dépasser une arête du support laminaire. Sur les 99 pointes entières, 95 possèdent en effet un dos convexe (96\%) alors que seulement 3 pointes possèdent un dos droit $(3 \%)$, la dernière ayant un dos irrégulier (1\%).

Une majorité de pointes à dos possède un bord opposé au dos entièrement retouché ou dont la retouche est très développée. Sur les 99 pièces entières, 60 portent une retouche totale ou partielle importante (61\%), 27 pièces ne portent aucune retouche ( $27 \%$ ) et 11 pièces portent une retouche partielle très peu développée $(11 \%)$. Celle-ci est très majoritairement réalisée de manière directe, seules 3 pièces possédant une retouche inverse. Lorsque la retouche est partielle, celle-ci affecte principalement les extrémités de la pièce, notamment l'extrémité apicale. Cette retouche donne un aspect légèrement convexe au bord opposé dans un effet de symétrie avec la convexité du dos par rapport à l'axe joignant les deux extrémités. Les pointes dont le bord opposé au dos n'est pas retouché

\section{Effectif}

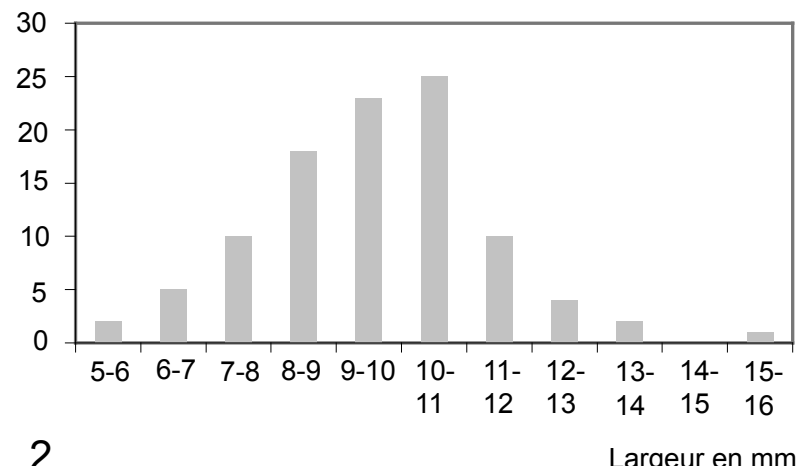

Effectif

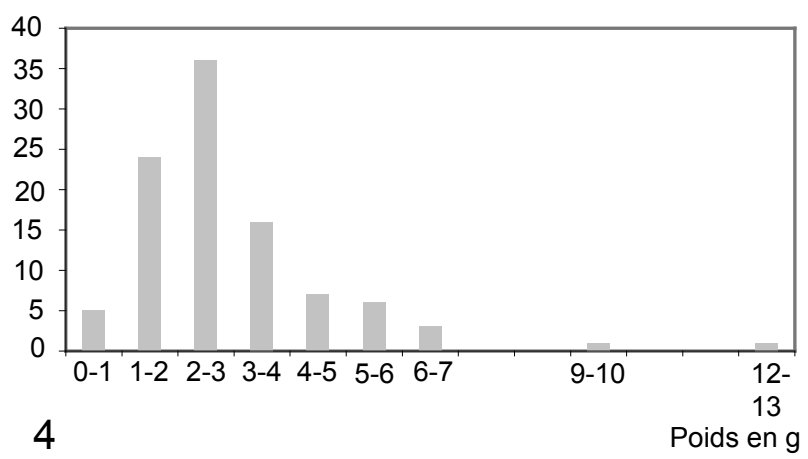

Figure 5 - Morphométrie des 99 pointes à dos entières du niveau inférieur IV du Gravettien d'Isturitz. Collection Saint-Périer, M.A.N.

Figure 5 - Morphometry of the intact 99 backed points from Isturitz gravettian level IV. Saint-Périer collection, M.A.N. 
sont toutes aménagées sur des supports laminaires aux bords naturellement convexes, convergents et effilés dans la partie distale et arrondis dans la partie proximale. L'objet recherché est très clairement biconvexe. L'extrémité apicale semble cependant être plus souvent élancée que la base : la largeur maximale ne correspond pas au milieu de la pièce mais se rapproche du tiers inférieur. Ceci explique l'investissement plus important généralement réalisé dans la retouche de la partie apicale du bord opposé au dos. La fonction des retouches directes semble ainsi d'appointer les deux extrémités de l'objet et de corriger, si nécessaire, la symétrie de la pièce.

\subsubsection{4 - Les retouches inverses rasantes}

Concernant les retouches inverses rasantes des extrémités, nous pouvons noter que sur 99 pièces entières ou presque entières, 35 ne portent aucune retouche inverse rasante des extrémités (35\%), 27 portent une retouche des extrémités basales et apicales (27\%), 28 une retouche seule de la base $(28 \%)$ (5 pièces possèdent cependant une légère cassure de l'extrémité apicale qui aurait pu être retouchée) et 9 une retouche de l'extrémité apicale uniquement $(9 \%)$.

Cette retouche affecte indifféremment tous les gabarits de pointes. Or, s'il s'agissait uniquement de retouches d'amincissement, la probabilité que ces dernières affectent principalement les grandes pièces et les plus épaisses serait plus importante. Bien que probable, cette hypothèse ne peut donc pas être retenue comme explication exclusive d'autant plus que de nombreuses retouches inverses rasantes ne sont pas totales et ne concernent qu'une partie de la largeur de la base.

En revanche, les retouches inverses rasantes sont plus fréquentes au niveau des bases. Ce phénomène pourrait s'expliquer par la nécessité de redresser la courbure longitudinale du support laminaire et par la réduction du talon. Mais il peut également s'expliquer, sans que les deux hypothèses ne soient exclusives, par la volonté d'un façonnage morphologique plus important des bases de manière à se rapprocher d'un certain canon. En effet, la morphologie des bases est beaucoup moins élancée et plus arrondie. Leur conception nécessite alors une retouche plus importante qui se développe sur l'ensemble de la circonférence de la base. Le caractère étroit de l'extrémité apicale, quant à lui, déterminera davantage l'utilisation d'une retouche moins envahissante et uniquement effectuée à partir du bord opposé au dos (fig. 6).

L'observation de la morphologie des bases va dans ce sens. Celles-ci sont en effet appointées et tendent parfois à être arrondies. Sur l'ensemble des 153 exemplaires de pointes entières et de bases, 95 bases sont appointées (62 \%), 26 possèdent une morphologie en troncature oblique convexe (17\%), 31 sont arrondies (20\%), 1 est une troncature droite rectiligne $(0,7 \%)$.

D'autre part, les retouches inverses rasantes des extrémités sont souvent difficiles à dissocier des retouches du bord opposé au dos. Certains exemplaires montrent ainsi une retouche alternante du bord opposé au dos (directe dans la plus grande partie puis inverse rasante aux

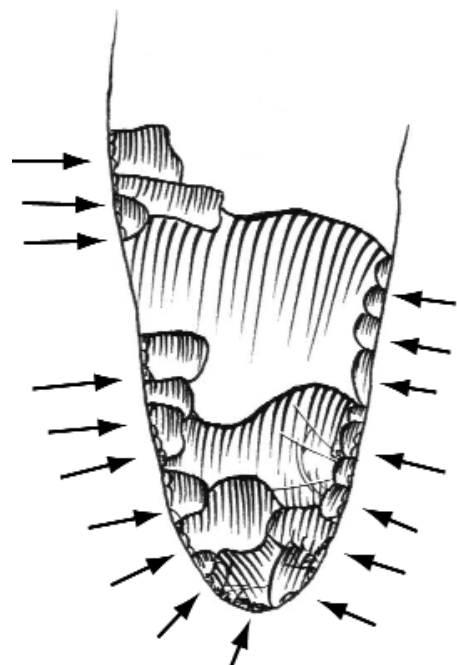

1

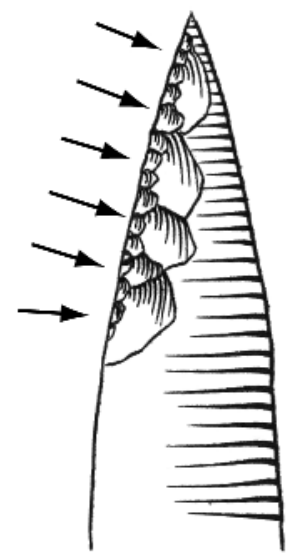

2
Figure 6 - Corrélation entre l'envahissement de la retouche inverse rasante et la morphologie de l'extrémité. Dessin A. Simonet. $N^{\circ} 1$ : la correction de la morphologie de la base moins élancée induit une fréquence plus prononcée d'une retouche inverse rasante totale.

$N^{\circ} 2$ : à l'inverse, l'extrémité apicale plus acérée induit d'autant plus une correction plus légère à partir d'un seul bord que le support laminaire est naturellement mince et effilé : la retouche inverse rasante est davantage partielle.

Figure 6 - Correlation between low angle inverse retouch invasion and extremity morphology. Drawing A. Simonet. $N^{\circ}$ 1: a wide base morphology correcting lead to a higher incidence of an invasive low angle inverse retouch.

$N^{\circ}$ 2: on the other hand, the sharper apical extremity lead to all the lighter correction from an only edge as the laminar blank is naturally thin and sharp: low angle inverse retouch is more partial.

extrémités) alors que d'autres pointes portent simplement une retouche inverse marginale d'une ou des deux extrémité(s).

\subsubsection{5 - Propriétés morphofonctionnelles}

La rectitude du support, la symétrie axiale de la pièce selon un axe joignant les deux extrémités, l'alignement systématique de l'apex sur l'axe de symétrie, la convexité du dos et du bord opposé au dos, constituent un ensemble de caractères qui définissent la pointe des Vachons comme un outil essentiellement perforant. La morphologie des fractures permet de considérer qu'une partie au moins des pointes a été utilisée comme armature de projectile. Les fractures retenues comme exclusivement diagnostiques d'une utilisation en pointe de projectile sont les fractures complexes en marche (fracture en flexion faciale ou transversale) et les fractures de type Spin-off bifaciale dont la longueur est égale et supérieure à $3 \mathrm{~mm}$. Les autres types de fractures complexes (fractures en plume, en charnière, Spin-off unifacial) ont également été prises en compte bien qu'elles puissent être liées au processus de fabrication ou 
à un phénomène post-dépositionnel (Fisher et al. 1984 ; O'Farrell 1996, 2004). Pour l'ensemble des deux collections Saint-Périer et Passemard, parmi les 179 fractures des pointes des Vachons prises en compte pour le niveau inférieur, 59 sont complexes (33 \%) et 120 sont simples (67 $\%)$. La proportion des fractures complexes à Isturitz est plus importante que celle obtenue expérimentalement lors de la fabrication (6\%) ou par le piétinement $(9 \%)$ confirmant l'utilisation majoritaire des pointes des Vachons comme pointe de projectile (fig. 7).

Néanmoins, le support très courbe de certaines pointes (8 exemplaires parmi les 99 pointes de la couche IV) s'oppose à une utilisation comme armature de projectile. Par ailleurs, aucune de ces pièces ne porte de fracture complexe. Leurs caractéristiques morphodimensionnelles sont néanmoins identiques (symétrie longitudinale, longueur moyenne). À tel point que sans la représentation de profil, il est impossible de les différencier des autres pointes des Vachons. Ces pointes souvent classées comme « atypiques " participent à l'argumentation d'une distinction fonctionnelle (armature de couteau/armature de projectile) au sein d'un même groupe typologique (fig. 4 - $n^{\circ} 1$ ).

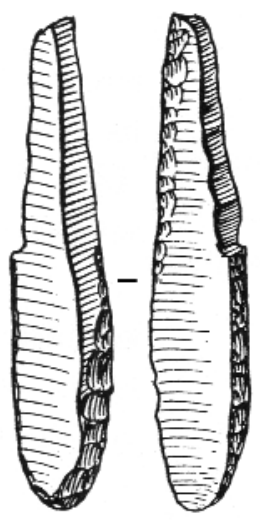

1
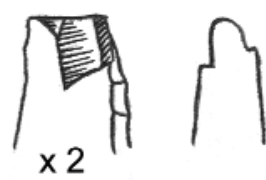
2

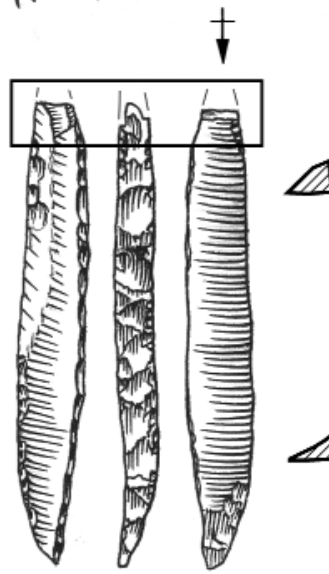

2
Figure 7 - Pointes des Vachons du Gravettien d'Isturitz portant une fracture complexe. $N^{\circ} 1$ : collection Saint-Périer, niveau $V$. M.A.N. D'après Saint-Périer 1952, fig. $106-n^{\circ} 2$.

$N^{\circ} 2$ : tamisage 2008, niveau IV. Dessin A. Simonet.

Figure 7 - Vachons points from Isturitz Gravettian with bending fracture. $N^{\circ}$ 1: Saint-Périer collection, level V. M.A.N. After Saint-Périer 1952, fig. $106-n^{\circ} 2$.

$N^{\circ}$ 2: 2008 sieving, level IV. Drawing A. Simonet.

\subsubsection{6 - La production}

II est difficile de reconnaître les schémas opératoires utilisés pour la confection d'un support laminaire transformé en pointe des Vachons étant donné l'existence d'un continuum au sein du débitage (grande lame/petite lame/grande lamelle/petite lamelle) présent à Isturitz. En fin d'exploitation, la majorité des nucléus sont à éclats ou à éclats laminaires. Toutefois, les supports montrent une rectitude et des gabarits qui sont parfaitement cohérents avec les rares nucléus laminaires dont l'exploitation n'a pas été poursuivies pour diverses raisons (fig. 8). Ceux-ci sont aussi bien à un ou deux plans de frappe. La mise en forme du volume est sommaire et le dos ainsi que les flancs peuvent rester corticaux. La progression du débitage est majoritairement frontale avec une table très rectiligne, étroite et cintrée. Le principe de l'autoentretien avec une alternance de séries d'extraction de produits laminaires à partir de tables sécantes est un grand principe du débitage gravettien d'Isturitz. Les néo-crêtes sont très rares et le rythme du débitage prend un aspect très rapide. Ces tables sécantes montrent que, dans le Gravettien à Noailles d'Isturitz, plein débitage et entretien d'une part, réimplantation et continuité du débitage d'autre part, sont des principes fusionnels. Ces schémas opératoires sont appliqués sur des nucléus qui subissent une diminution progressive de leur gabarit. Les pointes des Vachons, selon leur dimension, correspondent à l'aménagement de supports issus d'un moment plus ou moins avancé du débitage sans que les principes de gestion du volume ne s'en trouvent modifiés.

\subsection{3 - Proposition pour une nouvelle définition}

De l'étude des exemplaires des pointes à dos d'Isturitz, il ressort que l'utilisation de la retouche inverse rasante est une modalité permettant essentiellement la correction de la morphologie des extrémités. D'autres modalités sont néanmoins envisageables comme I'utilisation d'une retouche directe. Davantage que la présence d'une retouche inverse rasante, c'est l'élégance de ces pointes à la morphologie étroite et symétrique qui est un critère unificateur extrêmement puissant. Au-delà de la variabilité de leur gabarit, les pointes à dos du niveau IV possèdent une grande homogénéité conceptuelle (fig. 2, 3, 4). Les cas déviants sont rares et montrent clairement le concept raté sous-jacent (fig. 9). En définitive, le concept recherché est une pointe épaisse, étroite et lancéolée. La retouche inverse rasante des extrémités est un moyen particulièrement soigné d'obtenir ce résultat. Dans l'exemple d'Isturitz, l'emploi d'une retouche inverse rasante au niveau des extrémités qui était à l'origine de la création du type ne serait plus un critère de différentiation typologique. La conséquence est qu'il pourrait exister, dans d'autres sites, des pointes à dos portant une retouche inverse rasante qui ne seraient peut-être pas des pointes des Vachons. 


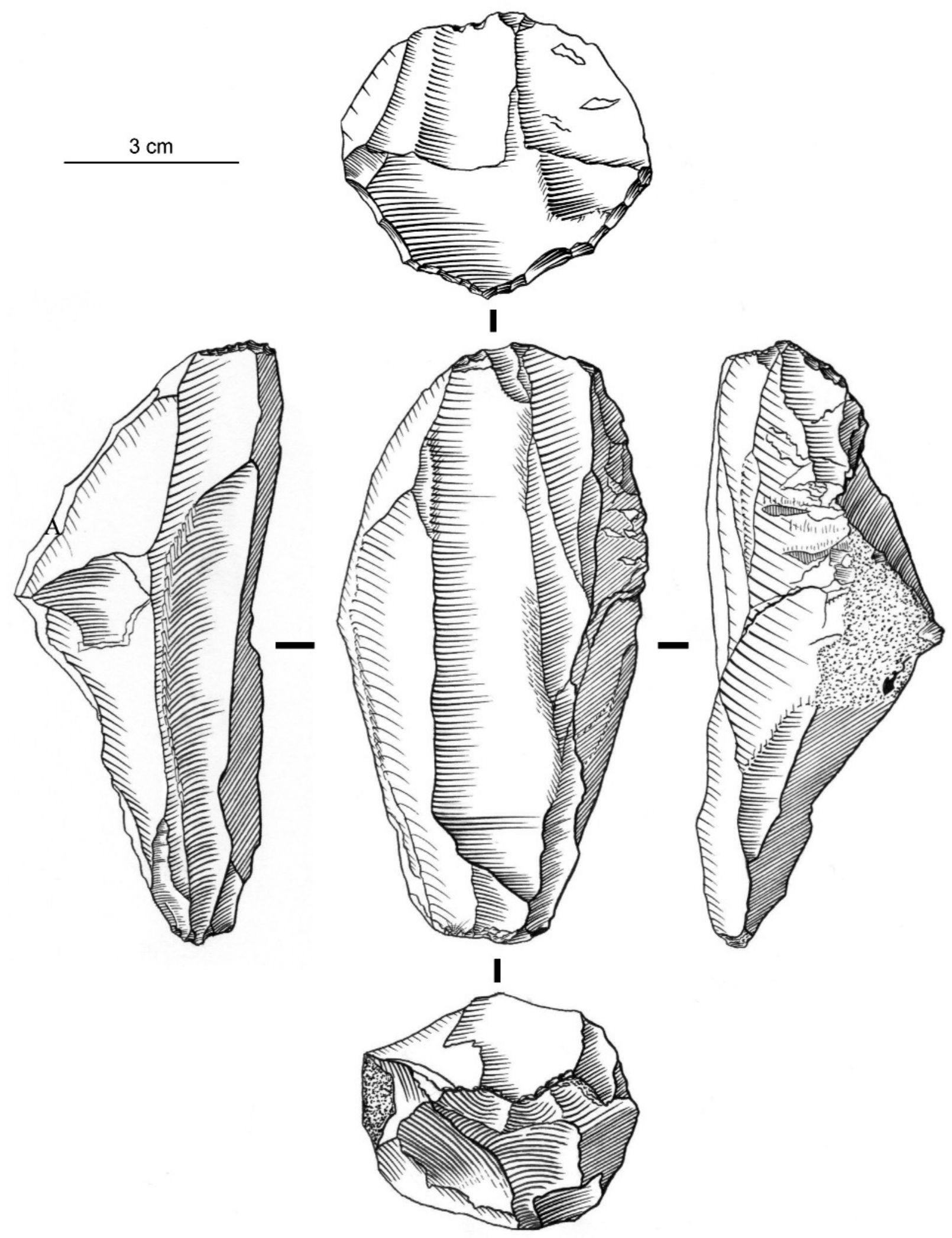

Figure 8 - Isturitz. Nucléus à partir duquel ont probablement été extraits des supports de pointes des Vachons. Collection Saint-Périer, niveau IV. M.A.N. La présence de négatifs de grands enlèvements laminaires au dos du nucléus (A) indique la réorientation du volume. La pièce a subi l'action du feu. Dessin A. Simonet.

Figure 8 - Isturitz. Core that had probably gave Vachons points blanks. Saint-Périer collection, level IV. M.A.N. Negatives of big laminar removal in the back of the core $(A)$ indicate the reorientation of the volume. Drawing $A$. Simonet. 


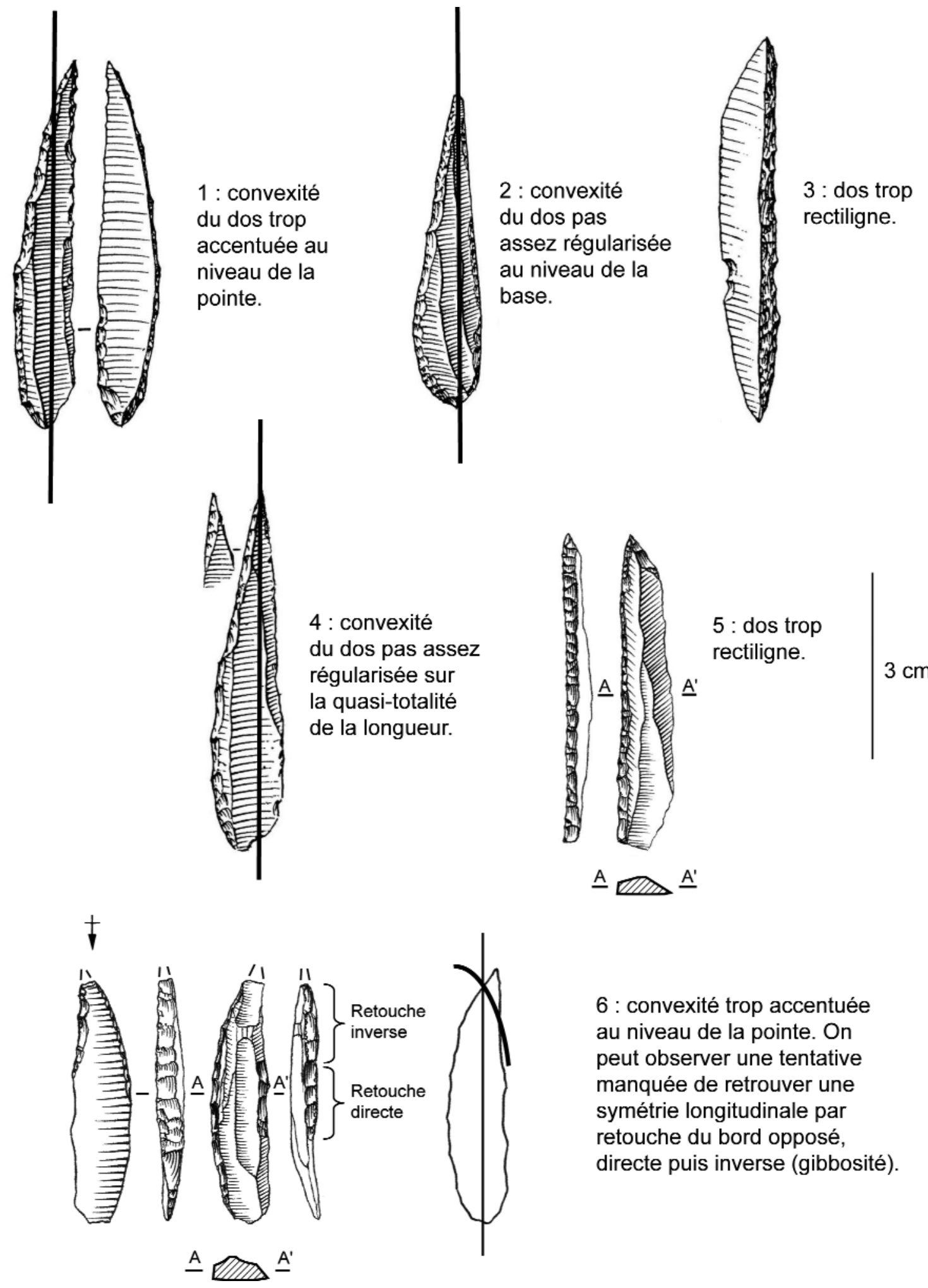

Figure 9 - Quelques exemples de pointes des Vachons déviantes. Isturitz, niveau IV. Nos 1 à 4 : collection Saint-Périer. M.A.N. D'après Saint-Périer 1952, fig. $41-n^{\circ}$ 4, 14, 17, 20. №s 5 et 6 : tamisage 2005. Hasparren. Dessin A. Simonet.

Figure 9 - A few examples of deviant Vachons points. Isturitz, level IV. Nos 1 to 4: Saint-Périer collection. M.A.N. After Saint-Périer 1952 , fig. $41-n^{\circ} 4$, 14, 17, 20. Nos 5 and 6: Isturitz, 2005 sieving of the Saint-Périer clearings, level IV. Hasparren. Drawing A. Simonet. 


\section{2 - Les données des niveaux 4 des abris 1 et 2 des Vachons (Charente, France)}

\subsection{1 - Séquence archéologique, critique et évaluation}

Les principales fouilles des abris 1 et 2 des Vachons ont été conduites par $\mathrm{M}$. Coiffard et $\mathrm{M}$. le chanoine Bouyssonie entre 1929 et 1937 (Bouyssonie 1948 ; Bouyssonie et Sonneville-Bordes 1956 ; Sonneville-Bordes 1960). Les deux hommes se sont répartis les secteurs : au chanoine l'abri 1 et à Coiffard l'abri 2. Dans chacun des deux abris, le niveau 4 est calé entre un niveau sous-jacent de Gravettien à nombreuses pointes de la Font-Robert et un
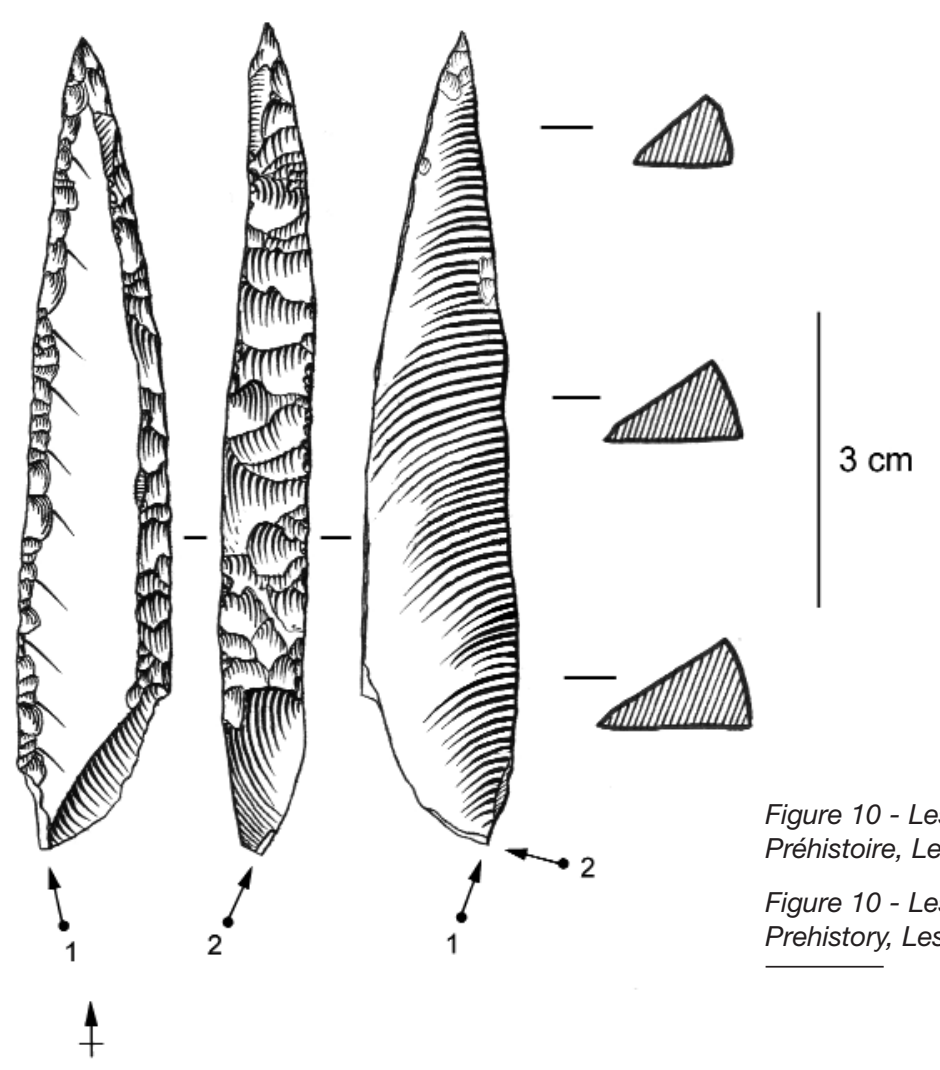

niveau sus-jacent de Gravettien à lames à troncature oblique. Ce niveau offre une importante collection de pointes des Vachons, élégante singularité dont Coiffard fut le premier à souligner l'importance (Coiffard 1914, 1922, 1937). Quelques burins du Raysse et quelques burins de Noailles argumentent une attribution au Gravettien moyen bien qu'une association stricte des différents éléments de l'assemblage ne soit pas encore démontrée. De la collection, bien connue grâce aux publications de Bouyssonie et Sonneville-Bordes (Bouyssonie 1948 ; Bouyssonie et Sonneville-Bordes 1956), seules les pièces gardées par Coiffard ont été préservées. Celles-ci sont actuellement conservées à l'Institut de Paléontologie Humaine à Paris et au Musée national de Préhistoire des Eyzies-de-Tayac. Notre étude repose sur la seule série du Musée des Eyzies qui n'offre malheureusement pas le débitage.

\subsection{2 - Présentation de l'industrie des niveaux 4, critique et évaluation de son homogénéité}

\subsubsection{1 - L’abri 1}

\section{Les pointes à dos}

Les 22 pointes à dos de l'abri 1 sont essentiellement constituées d'extrémités basales $(\mathrm{N}=10)$ mais aussi de quelques extrémités apicales $(\mathrm{N}=3)$. Quatre exemplaires entiers ou presqu'entiers sont néanmoins présents (fig. 10 et tabl. 2).

\begin{tabular}{|l|r|r|r|}
\hline & Abri 1 & Abri 2 & Total \\
\hline Pointe à dos & 22 & 39 & 61 \\
\cline { 2 - 4 } $\begin{array}{l}\text { Pointe à dos entière ou presqu'entière } \\
\text { Partie basale }\end{array}$ & 4 & 5 & 9 \\
\cline { 2 - 4 } $\begin{array}{l}\text { Partie mésiale } \\
\text { Partie apicale }\end{array}$ & 10 & 21 & 31 \\
\cline { 2 - 4 } Partie basale/apicale? & 1 & 2 & 3 \\
\cline { 2 - 4 } & 3 & 0 & 3 \\
\cline { 2 - 4 } Ebauche probable de pointe à dos & 4 & 11 & 15 \\
\hline Ebauche possible pointe à dos & 1 & 23 & 33 \\
\hline Lame à dos rectiligne & 4 & 10 & 14 \\
\hline Lamelle à retouche marginale appointée & 0 & 1 & 1 \\
\hline Lamelle à dos/Micropointe à dos & 0 & 1 & 1 \\
\hline Ebauche de Pièces à dos diverses & 3 & 1 & 4 \\
\hline Total & 11 & 21 & 32 \\
\hline
\end{tabular}

Tableau 2 - Décompte 2008 des armatures des Vachons, niveau 4. Collection Coiffard. Musée national de Préhistoire, Les Eyzies-de-Tayac.

Table 2 - 2008 count of Les Vachons' points, level 4. Coiffard collection. National museum of Prehistory, Les Eyzies-de-Tayac. 


\section{Morphométrie}

Les longueurs des 4 pointes entières sont respectivement de 41, 48, 52 et $69,5 \mathrm{~mm}$. La largeur moyenne des pointes entières et fracturées est de 9,2 $\mathrm{mm}$ pour une épaisseur moyenne de 4,8 mm (fig. 11).

\section{Epaisseur en $\mathrm{mm}$}

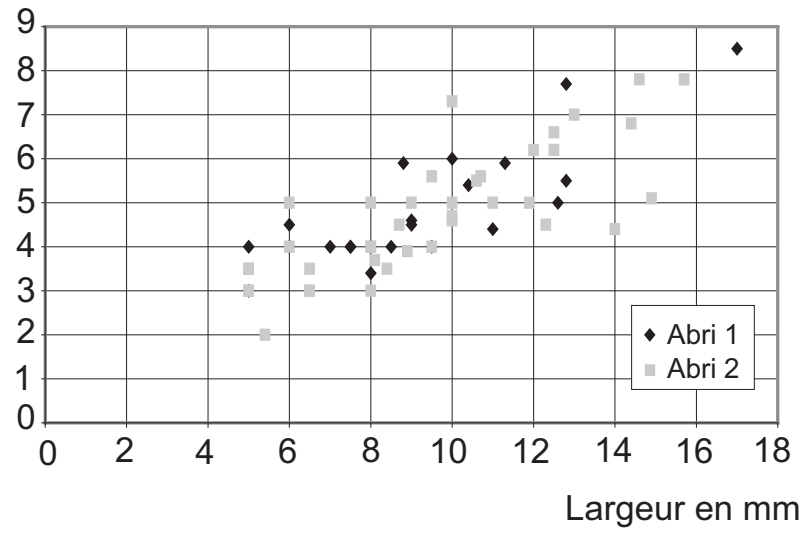

Figure 11 - Rapport largeurlépaisseur des pointes à dos des Vachons. Abris 1 et 2, niveau 4.

Figure 11 - Width/thickness ratio of backed points of Les Vachons. Shelters 1 and 2, level 4.

\section{Caractères morphotechniques}

En ce qui concerne la latéralisation, 12 pointes à dos possèdent un dos dextre, 6 ont un dos senestre et 4 sont indéterminables. Le dos est majoritairement aménagé par retouche abrupte directe ( 11 exemplaires), mais aussi par retouche abrupte directe et légèrement croisée aux extrémités (6 exemplaires) et par retouche strictement croisée (5 exemplaires). Le bord opposé au dos est très souvent retouché (16 cas sur 22). La retouche est très majoritairement directe (13 exemplaires) mais peut aussi être inverse (2 exemplaires) ou alternante (1 exemplaire qui possède une légère retouche inverse discontinue en complément de la retouche directe). Cette retouche du bord opposé affecte préférentiellement les extrémités ( 9 exemplaires) mais concerne assez souvent la totalité ou la quasi-totalité du bord (7 exemplaires de retouche directe importante).

\section{Les retouches inverses rasantes}

La morphologie de la base est principalement appointée (6 exemplaires) mais peut aussi être arrondie (4 exemplaires) et plus rarement aménagée par troncature oblique convexe (1 exemplaire). Les bases appointées correspondent à des supports qui sont naturellement étroits à cette extrémité tandis que les bases arrondies et les troncatures semblent davantage correspondre à des modalités d'aménagement de supports plus larges. Sur les 21 pièces comportant une ou deux extrémités conservées, 9 portent une retouche inverse rasante d'une extrémité (5 de l'extrémité basale, 1 de l'extrémité apicale et 3 d'une extrémité indéterminée). II s'agit à chaque fois de retouche inverse rasante totale. Les 4 pointes entières ne comportent aucune retouche inverse rasante de leurs extrémités. Les 4 bases arrondies portent une retouche inverse rasante totale tandis que 5 bases appointées ne portent aucune retouche inverse rasante ( 1 seule base appointée porte une retouche inverse rasante). La base tronquée ne porte aucune retouche inverse rasante. II semble par conséquent exister une corrélation étroite entre la présence d'une retouche inverse rasante et la morphologie de la base.

\subsubsection{2 - L'abri 2}

\section{Les pointes à dos}

Les 39 pointes à dos de l'abri 2 sont essentiellement constituées d'extrémités basales $(\mathrm{N}=21)$. Seules 5 pointes sont entières (fig. 12 et tabl. 2).

\section{Morphométrie}

Les longueurs des 5 pointes entières sont respectivement de 27, 42, 48, 62 et $69 \mathrm{~mm}$ (fig. 11 - $\mathrm{n}^{\circ}$ 2). La largeur moyenne des pointes entières et fracturées est de $9,5 \mathrm{~mm}$ pour une épaisseur moyenne de $4,7 \mathrm{~mm}$ (fig. 12). Trois fragments de pointes à dos de l'abri 2 portent une fracture complexe (fig. $12-\mathrm{n}^{\circ \mathrm{s}} 3$ et 5 ).

\section{Caractères morphotechniques}

En ce qui concerne la latéralisation, 21 pointes possèdent un dos dextre, 5 ont un dos senestre et 13 sont indéterminables. Le dos est majoritairement aménagé par retouche abrupte directe (18 exemplaires) mais aussi par retouche abrupte directe et légèrement croisée aux extrémités ( 6 exemplaires) et par retouche strictement croisée (15 exemplaires). Une retouche directe du bord opposé semble être davantage utilisée pour réduire un support plus étroit. Celui-ci est très souvent retouché (28 cas sur 39 ). La retouche est le plus souvent directe (20 exemplaires) mais elle peut aussi être occasionnellement inverse (4 exemplaires), à la fois directe et inverse (3 exemplaires) voire alternante (1 exemplaire). Cette retouche du bord opposé affecte majoritairement la totalité (12 exemplaires) ou une partie importante du bord (12 exemplaires portent une retouche qui est égale ou supérieure à la moitié de la longueur). Elle est plus rarement d'amplitude peu importante (5 exemplaires) et concerne alors principalement les extrémités.

\section{Les retouches inverses rasantes}

La morphologie de la base est très souvent large (18 exemplaires dont 13 arrondies et 3 aménagées par troncature oblique convexe), plus rarement appointée (7 exemplaires). Une majorité de bases à morphologie appointée ne porte aucune retouche inverse rasante (4 exemplaires sur 7) tandis qu'une large majorité de base à morphologie plus large porte une retouche inverse rasante totale (14 exemplaires sur 18). Nous retrouvons dans l'abri 2 la même corrélation observée dans l'abri 1 entre la morphologie de la base et la présence d'une retouche inverse rasante bien que le rapport de proportion entre les pointes à dos à base large et celles à base étroite soit inversé. II s'ensuit que la retouche inverse rasante semble 

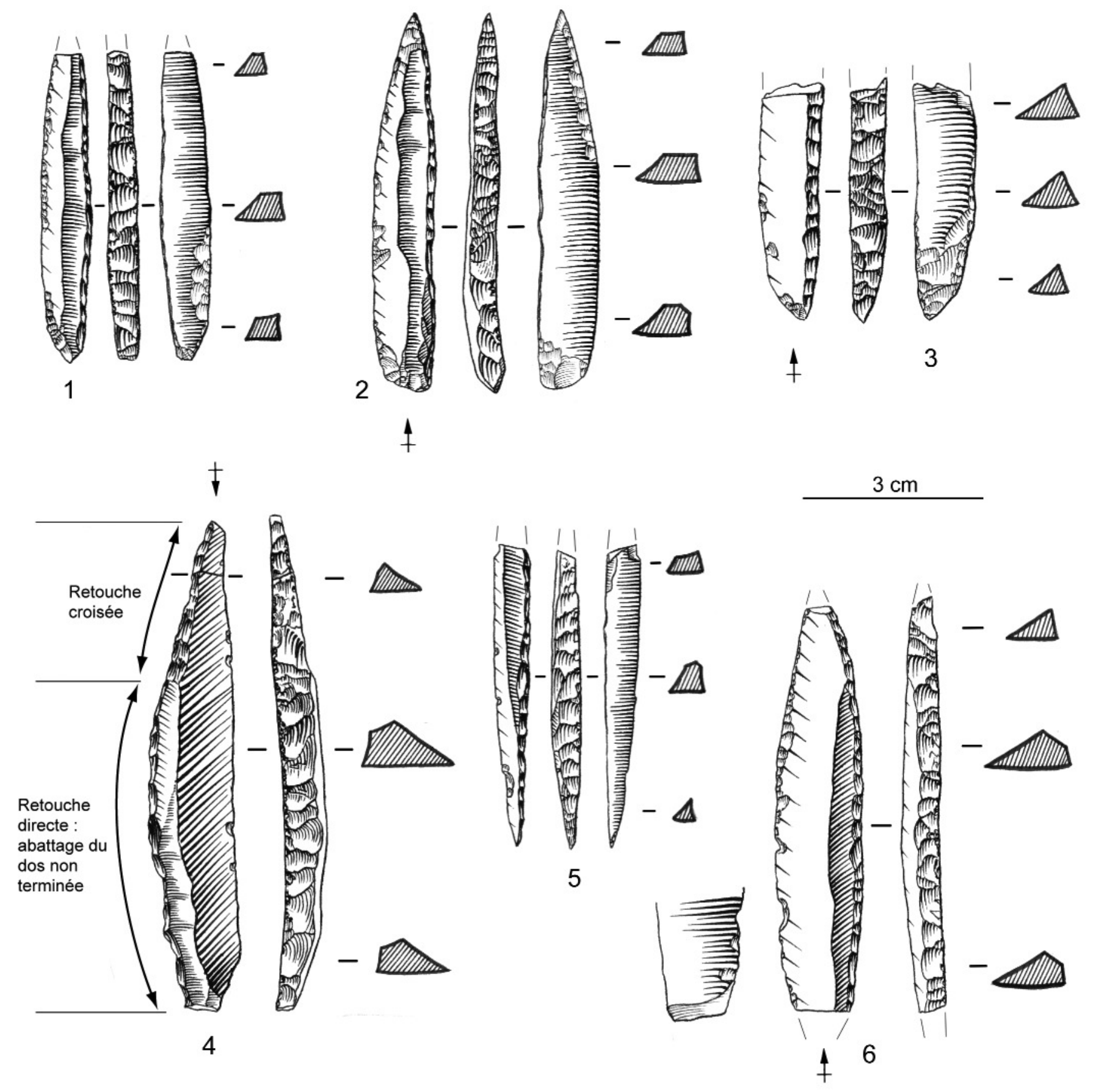

Figure 12 - Les Vachons, abri 2, couche 4. Pointes à dos. Musée national de Préhistoire, Les Eyzies-de-Tayac. Collection Coiffard. Dessins A. Simonet.

Figure 12 - Les Vachons, shelter 2, level 4. Backed points. National museum of Prehistory, Les Eyzies-de-Tayac. Coiffard collection. Drawings A. Simonet. 
correspondre au procédé technique utilisé pour façonner la base selon la forme recherchée.

\subsection{3 - Unité des pointes à dos des niveaux 4 des Vachons}

De ces constatations, il ressort une grande similarité des assemblages de pointes à dos de l'abri 1 et de l'abri 2. Dans chacun des deux petits abris contigus, les pointes possèdent des gabarits identiques (fig. 11). Leur morphologie générale respecte une recherche de symétrie mais leur base est très souvent aménagée par troncature oblique convexe. Le dos est principalement aménagé par retouche directe tandis que la délinéation du bord opposé au dos est très souvent corrigée sur sa plus grande longueur à l'aide d'une retouche directe. Le dos est majoritairement dextre. Une retouche inverse rasante est très souvent utilisée dans la correction morphologique des extrémités. Dans chacun des deux abris, les fractures complexes indiquant l'utilisation d'une partie au moins des pointes comme armature de projectile sont rares (inexistantes dans l'abri 1, 3 indices dans l'abri 2). En revanche, de nombreuses ébauches dont la proportion dépasse celle des pointes à dos sont présentes dans chacun des deux abris (fig. 12 - $\mathrm{n}^{\circ}$ 4). Elles témoignent de l'importance d'une activité de confection de pièces à dos et de l'exploitation d'un silex local d'excellente qualité, de couleur noire. Seule différence, la morphologie de la base des pointes plus généralement appointée dans l'abri 1 et arrondie dans l'abri 2 pourrait résulter de la faiblesse de l'échantillonnage des pointes de l'abri 1. De facto, il nous semble pertinent de corréler les assemblages des niveaux 4 des deux abris au sein d'un même ensemble chronoculturel à défaut de pouvoir affirmer leur contemporanéité.

\section{3 - Isturitz et Les Vachons : unité et variabilité des pointes à dos}

Le gisement des Vachons est le site éponyme de la pointe des Vachons qui se retrouve associée au Gravettien à burins de Noailles du niveau 4. La grotte d'Isturitz, quant à elle, a offert le décompte connu le plus important de pointes à dos rapportées au Gravettien à burins de Noailles. Une étude comparée entre les deux sites a donc un fort potentiel attractif.

Les pointes à dos de la grotte d'Isturitz sont confectionnées sur des supports rectilignes, épais et de régularité variable, extraits de nucléus cintrés à un ou deux plans de frappe. Leur morphologie générale est élancée, symétrique selon un axe longitudinal joignant les deux extrémités, et lancéolée étant donné que la largeur maximale ne correspond pas au milieu de la pièce mais se rapproche du tiers inférieur. La base est majoritairement appointée, plus rarement arrondie ou aménagée par troncature oblique convexe. La délinéation du bord opposé au dos est très généralement corrigée par retouche directe mais ce dernier peut être laissé brut si le tranchant de la lame est naturellement convexe et effilé en partie distale. Le dos, aussi bien dextre que senestre, est confectionné par percussion, par retouche majoritairement croisée mais aussi directe. Enfin, la morphologie appointée des extrémités est fréquemment conçue grâce à l'utilisation d'une fine retouche inverse rasante. Malgré la variabilité des gabarits, les pointes à dos du niveau IV des fouilles Saint-Périer présentent une grande homogénéité conceptuelle.

Les pointes à dos des Vachons possèdent comme caractéristiques communes à Isturitz, leur gabarit (fig. 13), leur support épais qui semble être extrait à l'aide de modalités identiques comme l'illustrent les deux uniques nucléus laminaires à tables opposées-décalées que nous avons pu observer, une morphologie générale qui répond à une exigence de symétrie selon un axe longitudinal joignant les deux extrémités et une utilisation insistante d'une retouche inverse rasante afin de corriger la morphologie des extrémités. Les pointes à dos des Vachons se distinguent néanmoins par un dos aménagé par retouche majoritairement directe, par des bases arrondies alors que les bases appointées sont préférées à Isturitz ainsi que par une latéralisation très majoritairement dextre (tabl. 3).

Derrière ces quelques divergences, l'observation comparée des pointes à dos d'lsturitz et des Vachons dévoilent une forte unité. D'une part, l'exigence de symétrie fédère l'ensemble de ces pointes à dos et se présente comme un critère d'identification diagnostique. D'autre part, si les longueurs varient considérablement entre les sites et au sein même d'un assemblage, les largeurs et les épaisseurs de l'ensemble des pointes à dos sont très proches avec un rapport largeur/épaisseur approximatif de $10 \mathrm{~mm}$ pour $5 \mathrm{~mm}$ (fig. 13). Cette recherche d'épaisseur, proportionnellement à l'étroitesse de l'armature, est le deuxième point commun. Autre caractéristique inter-sites, l'aménagement du dos à l'aide d'une percussion rapide tranche avec la délicatesse de la correction du bord opposé et de la retouche inverse des extrémités.

En définitive, la recherche de symétrie et d'épaisseur et l'identité inter-sites du rapport largeur/épaisseur induisent l'hypothèse d'un emmanchement axial très normé avec un système de mortaise d'environ $5 \mathrm{~mm}$ de largeur (fig. 14). Cet emmanchement identique pourrait être le critère unificateur fort des pointes à dos gravettiennes d'Isturitz et des Vachons.

\section{3 - Synthèse}

\section{1 - Pour une nouvelle définition de la pointe des Vachons}

Malgré une marge de variabilité morphologique dont l'interprétation reste à approfondir (influence de la matière première ?), nous pouvons d'ores et déjà mettre en avant l'existence de caractéristiques communes générales (fig. 15). Dans l'attente d'une comparaison bien plus large des pointes à dos gravettiennes sur un plus grand nombre de sites, la nouvelle définition de la pointe des Vachons serait la suivante :

"Pointe à dos étroite, épaisse et symétrique. L'axe de symétrie correspond à l'axe longitudinal joignant les deux extrémités. La délinéation du dos est convexe dans un 


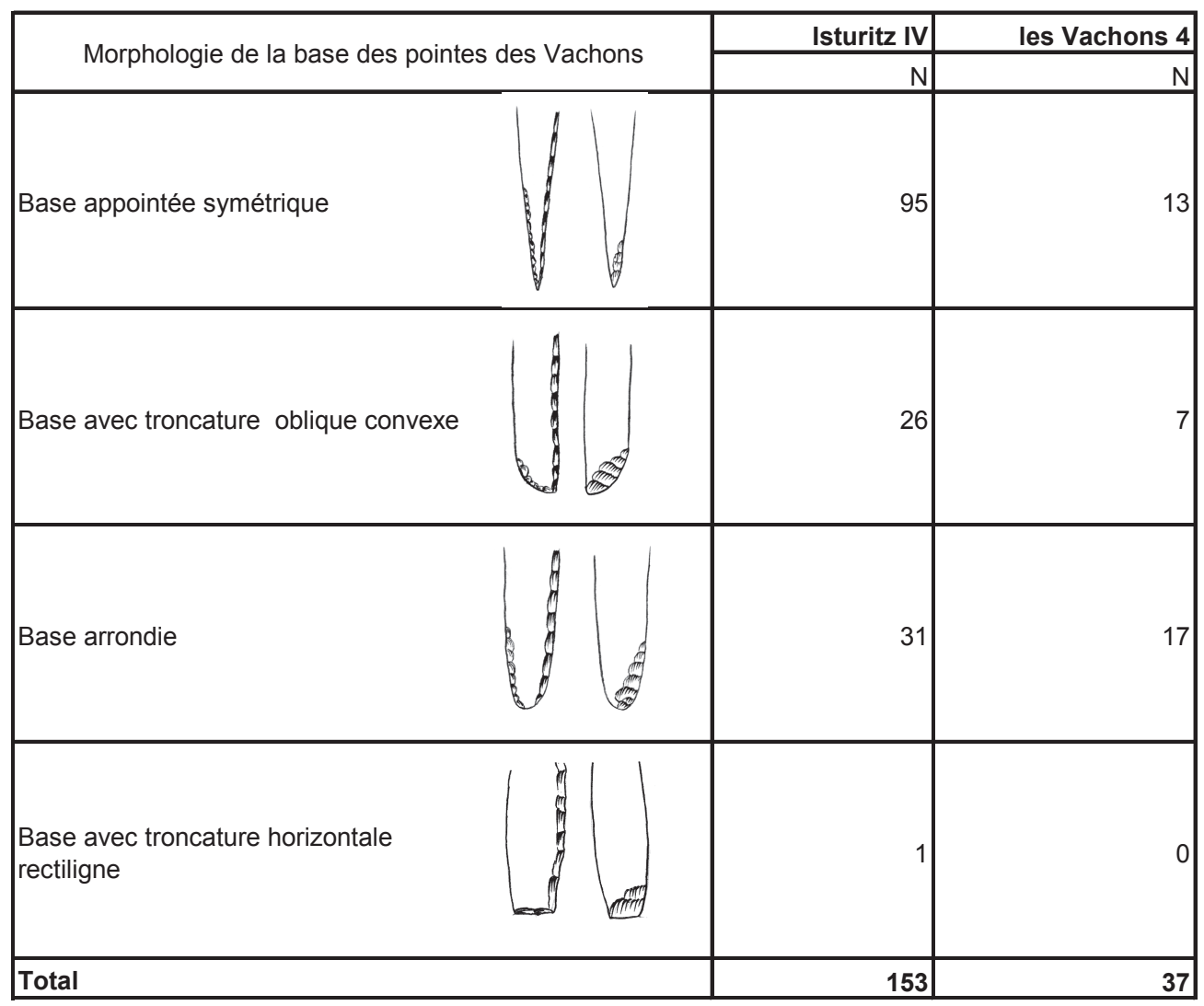

Tableau 3 - Répartition des pointes à dos d'Isturitz (niveau IV) et des Vachons (niveau 4) selon la morphologie de la base. L'effectif d'Isturitz ne concerne que les pointes entières ou presque tandis que celui des Vachons concerne les pointes entières associées aux bases.

Table 3 - Distribution of backed points from Isturitz (level IV) and Les Vachons (level 4) according to base morphology. The number of Isturitz' points only concern intact or practically intact points whereas the whole points and bases have been taking into account for Les Vachons.

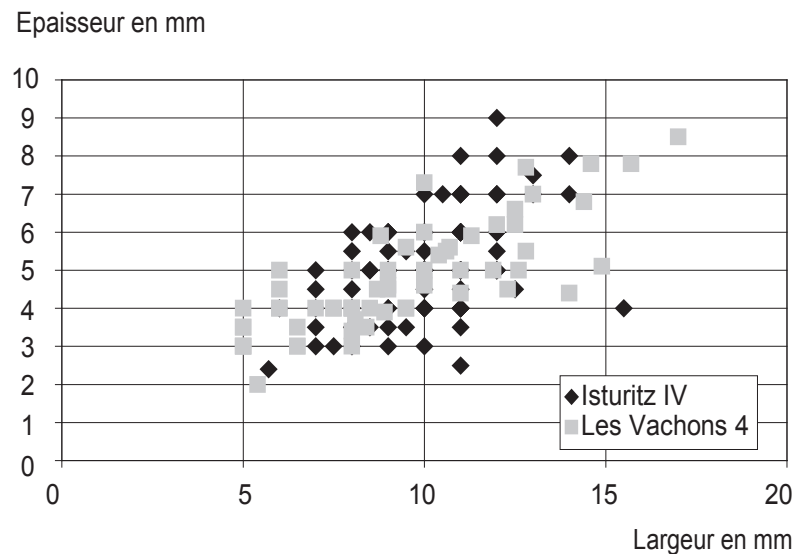

Figure 13 - Comparaison du rapport largeurlépaisseur des pointes des Vachons d'Isturitz (niveau IV) et des Vachons (niveau 4).

Figure 13 - Width/thickness ratio of Vachons points from Isturitz (level IV) compared with Les Vachons' (level 4).

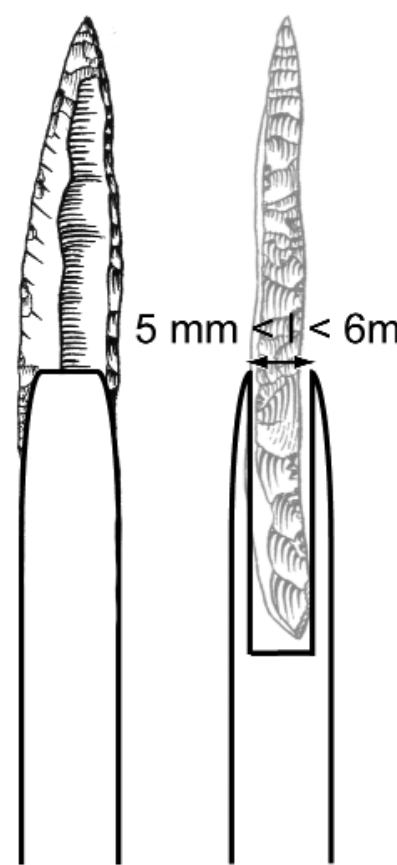

Figure 14 - Un emmanchement axial identique des pointes à dos du Gravettien à Noailles : un critère unificateur fort? Dessin A. Simonet.

Figure 14 - An identical axial hafting of backed points from Gravettian with Noailles burins: a high unifying diagnostic criterion ? Drawing A. Simonet. 


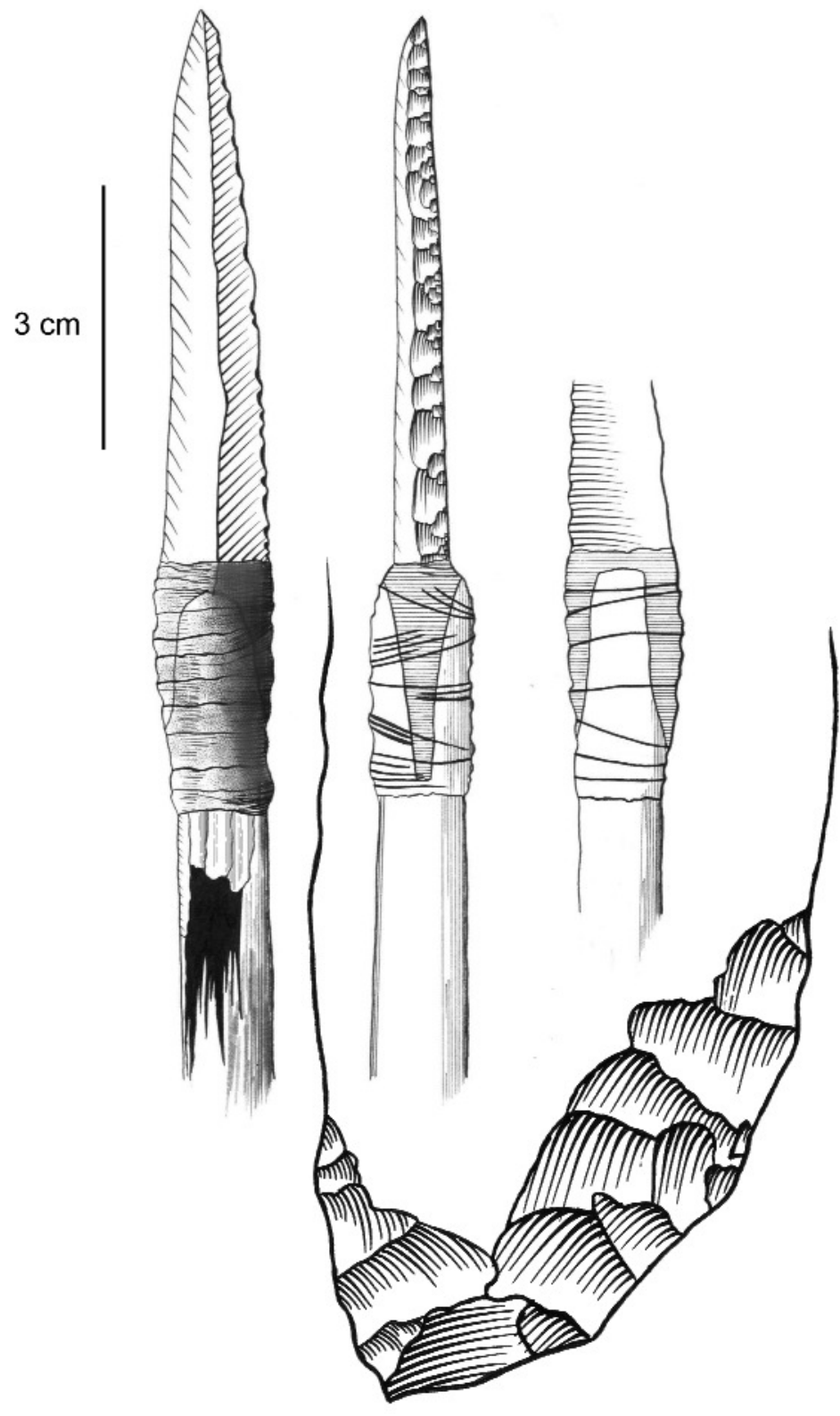

Figure 15 - Caractéristiques principales de la pointe des Vachons (dessin A. Simonet) :

- Morphologie lancéolée, étroite et symétrique voire bisymétrique.

- Épaisseur importante autour de 5 ou $6 \mathrm{~mm}$.

- Abattage majoritairement direct du dos par percussion.

- Base appointée ou arrondie par retouche inverse rasante et/ou semi abrupte.

Figure 15 - Main characteristics of Vachons point (drawing A. Simonet):

- Leaf shape, narrow and symmetrical or even bisymmetrical morphology.

- High thickness around 5 or $6 \mathrm{~mm}$.

- Back mainly made by direct retouch and by percussion.

- Pointed or rounded base made by low angle and/or semi-abrupt inverse retouch.

effet de symétrie par rapport au bord opposé. La forme de la pointe est nettement lancéolée étant donné que la largeur maximale ne correspond pas au milieu de la pièce mais plus généralement au tiers inférieur. Le dos est aménagé à l'aide d'un abattage total. Le bord opposé au dos est souvent régularisé par retouche directe notamment au niveau des extrémités afin d'affiner la symétrie. Enfin, un soin particulier s'exprime souvent lors de la finition de l'objet par l'utilisation éventuelle d'une retouche inverse rasante. 》

\section{2 - Évaluation de sa signification archéologique}

En partant de cette nouvelle définition élaborée sur l'étude comparée des pointes à dos de la grotte d'Isturitz et des
Vachons, un examen de la littérature associé à une première révision de certains assemblages permet leur identification dans un grand nombre de gisements (fig. 16).

Dans les Pyrénées, les pointes à dos gravettiennes sont en très grande majorité représentées par ce type (fig. 17). Nous retrouvons ainsi la pointe des Vachons dans les grands centres gravettiens pyrénéens que sont la grotte d'Isturitz (Saint-Périer 1952), la grotte du Pape à Brassempouy (Piette et de Laporterie 1898) ; (fig. 17 - $n^{\circ} 6$ ) et la grotte de Gargas (Breuil et Cheynier 1958) ; (fig. 17 $n^{\circ} 3$ ). Mais la pointe des Vachons se retrouve aussi dans des sites de plus faible ampleur comme Tarté (Bouyssonie 1939) ; (fig. 17 - $n^{\circ} 4$ ), Lezia (Chauchat 1973) ; (fig. $17-n^{\circ}$ 5) ou la Tuto de Camalhot (Vézian 1966) ; (fig. 17 - n²). 


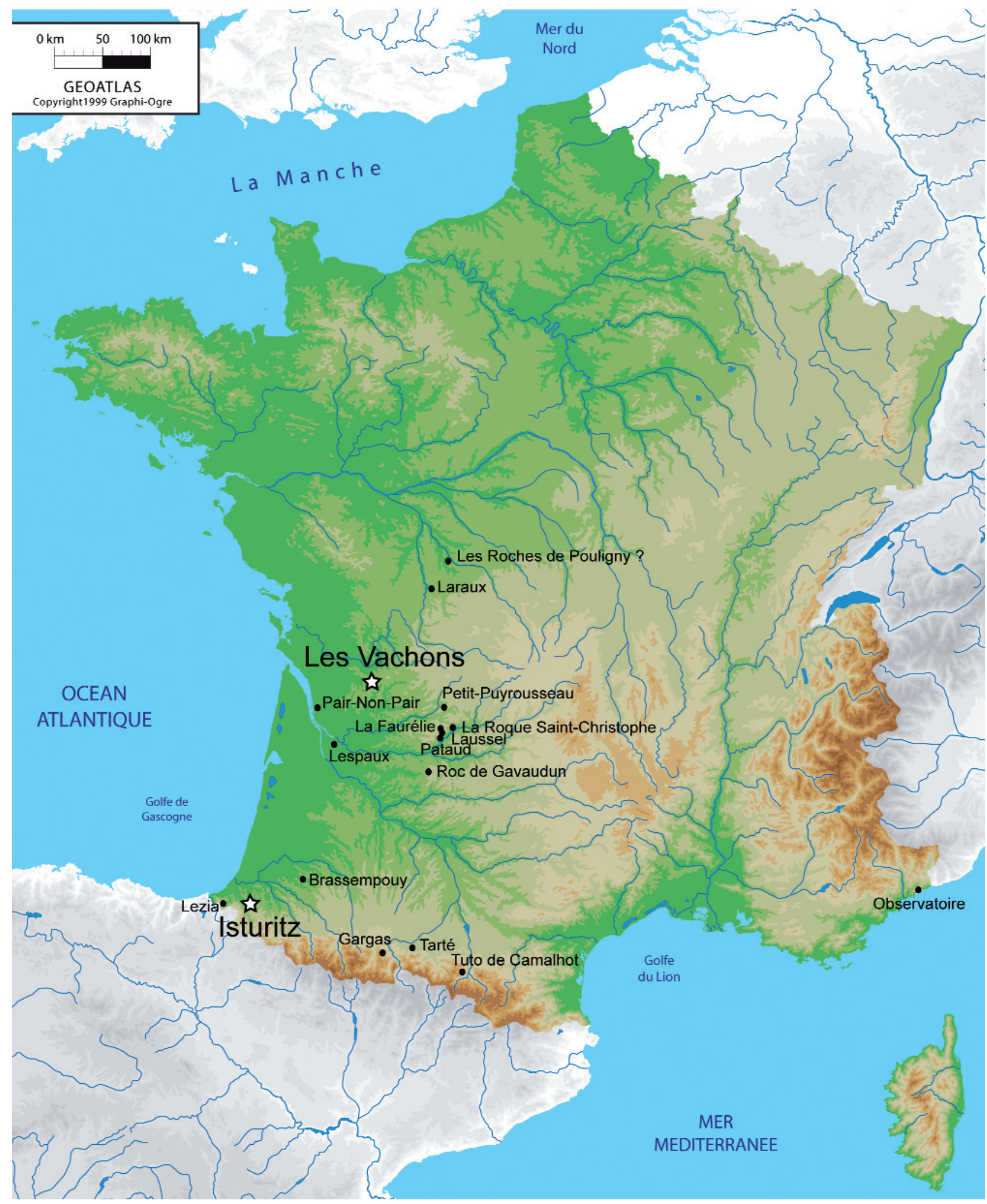

Figure 16 - Localisation des sites gravettiens à possibles pointes des Vachons mentionnés dans le texte.

Figure 16 - Location of gravettian sites with possible Vachons points mentioned in the text. 


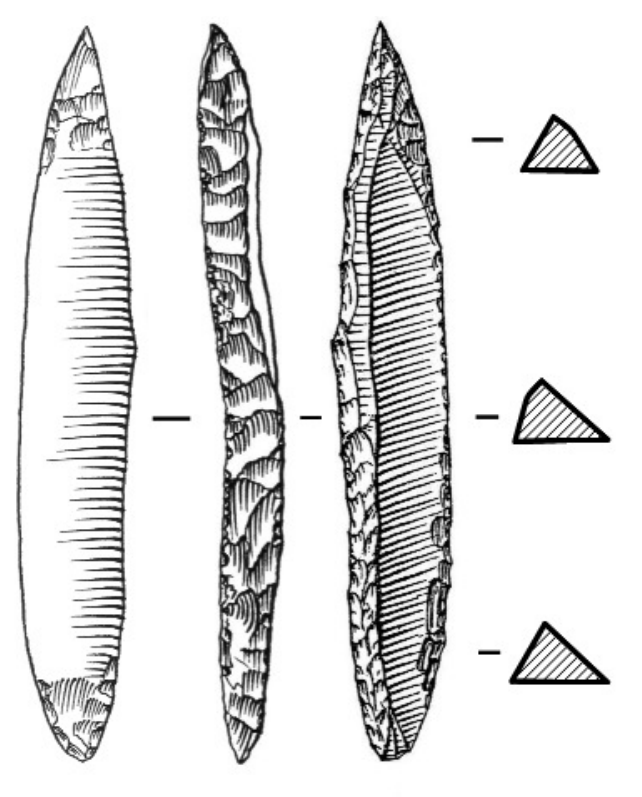

1

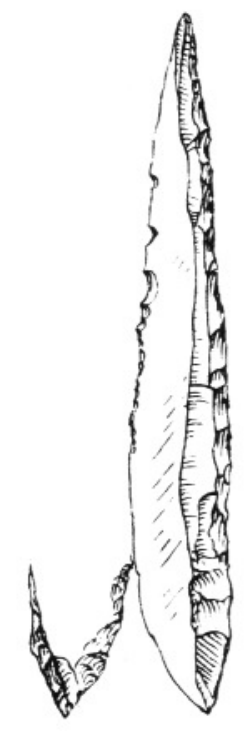

2

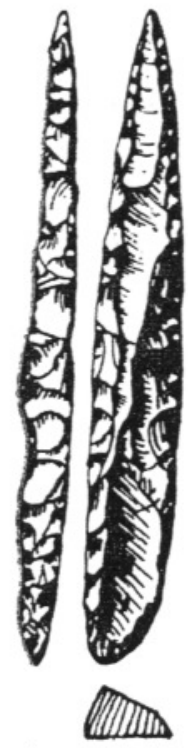

3

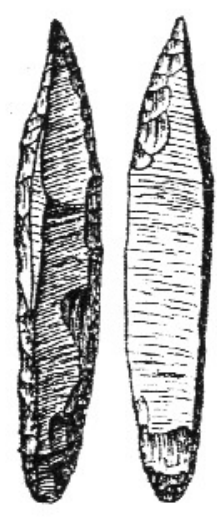

4

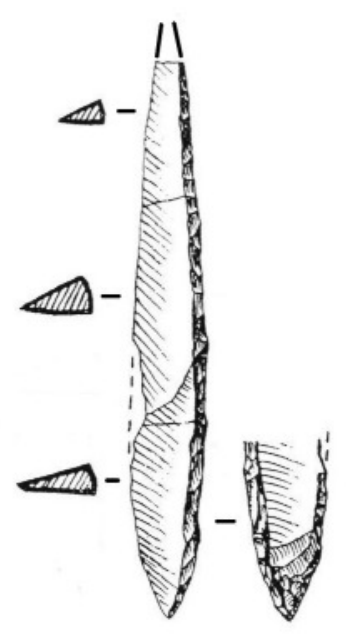

5

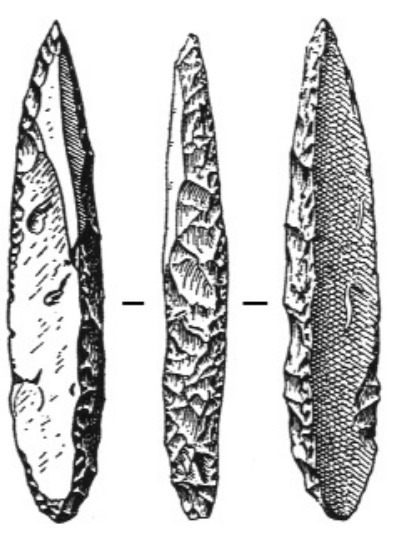

6

Figure 17 - Pointes des Vachons issues d'assemblages pyrénéens. $N^{\circ} 1:$ Isturitz, niveau IV, d'après Saint-Périer 1952, fig. $42-n^{\circ}$ 9, modifié. $N^{\circ} 2$ : la Tuto de Camalhot, d'après Vézian 1966, fig. $15-n^{\circ} 7 . N^{\circ} 3$ : Gargas, niveau 6, d'après Breuil et Cheynier 1958, pl. XI - $n^{\circ}$ 140. $N^{\circ} 4$ : Tarté, niveau supérieur, d'après Bouyssonie, 1939, fig. 8 - $n^{\circ} 1$. $N^{\circ} 5$ : Lezia, d'après Chauchat 1973, fig. $5-n^{\circ}$ 1. $N^{\circ} 6$ : Brassempouy, grotte du Pape, d'après Piette et De Laporterie 1898, fig. 23.

Figure 17 - Vachons points from Pyrenean assemblages. $N^{\circ}$ 1: Isturitz, level IV, after Saint-Périer 1952, fig. $42-n^{\circ} 9$, modified. $N^{\circ}$ 2: la Tuto de Camalhot, after Vézian 1966, fig. $15-n^{\circ}$ 7. $N^{\circ}$ 3: Gargas, level 6, after Breuil and Cheynier 1958, pl. XI - $n^{\circ}$ 140. $N^{\circ}$ 4: Tarté, upper level, after Bouyssonie 1939, fig. $8-n^{\circ}$ 1. $N^{\circ}$ 5: Lezia, after Chauchat 1973, fig. $5-n^{\circ}$ 1. $N^{\circ}$ 6: Brassempouy, grotte du Pape, after Piette and De Laporterie 1898, fig. 23. 
La pointe des Vachons se retrouverait dans le Lot-etGaronne au Roc de Gavaudun (Monmejean et al. 1964). Elles sont présentes en grand nombre en Gironde à l'abri Lespaux (Cousté et Krtolitza 1965 ; Krtolitza et Lenoir 1998) ; (fig. 18 - $n^{\circ}$ 6). La grotte de Pair-Non-Pair en offre quelques exemplaires de très belle facture (Breuil et Cheynier 1963) ; (fig. $18-\mathrm{n}^{\circ} 7$ ).

Nous la retrouvons ensuite en Charente dans le site éponyme. Dans le Périgord, la pointe des Vachons semble présente dans la couche 4 de l'Abri Pataud tandis qu'elle serait absente des couches 5 et 3 (Bricker dir. 1995) ; (fig. $18-n^{\circ} 1$ ). À Laussel, la majorité des pointes à dos ne sont pas des pointes des Vachons bien que certains exemplaires soient néanmoins présents, notamment au sein du petit assemblage de pièces lithiques découvert à proximité de la Vénus de Laussel (Lalanne et Bouyssonnie 1946) ; (fig. 18 - $n^{\circ} 4$ ). Elle pourrait également se retrouver à La Roque Saint-Christophe (fig. $18-n^{\circ} 3$ ), à la Faurélie (fig. $18-n^{\circ}$ 2) et au Petit-Puyrousseau (Sonneville-Bordes 1960). En revanche, Corbiac offre des pointes à dos anguleux dont la morphologie différente rappelle certains exemplaires de pointes à dos du niveau supérieur $C \mathrm{du}$ Gravettien d'Isturitz (O'Farrell 1996 ; Koslowski et Lenoir 1988 ; Simonet 2009, 2010) ; (fig.19 - $\left.n^{\circ} 1\right)$. Les pointes à dos entières ou presqu'entières de la couche 1 de Roc de Combe offrent une morphologie qui se rapprocherait également davantage des pointes à dos de Corbiac (Bordes et Labrot 1967 ; Sonneville-Bordes 2002 ; Koslowski et Lenoir 1988). D'après la seule consultation de la littérature scientifique, il est difficile de préciser si la pointe des Vachons est présente au Flageolet I (Rigaud 1982 ; Lucas 2000). Or, ce site fouillé récemment offre plusieurs niveaux de Gravettien moyen à burins de Noailles. Une étude du matériel serait très intéressante. Sans reprise du matériel, il est également impossible d'affirmer que la pointe des Vachons puisse être présente aux Jambes (Célérier 1967), à Laugerie-Haute, à la Ferrassie (Delporte dir. 1984), à l'abri Labattut ou à Oreille d'Enfer (Sonneville-Bordes 1960). Enfin, nous réservons le problème des micro-pointes des Vachons, telle qu'elles pourraient par exemple se retrouver à Rabier, pour de futurs travaux (Soriano 1998).

Plus au Nord, le site de Laraux dans la Vienne semble offrir de nombreux exemplaires de pointes des Vachons (Pradel et Chollet 1950 ; Pradel 1979 et fig. 18 - n 5). Ce type de pointe à dos serait peut-être présent en Indre à l'abri des Roches (Pradel 1965).

Enfin, cette pointe est absente des collections de la grotte des Enfants aux Balzi Rossi tandis qu'elle se retrouve dans la grotte de l'Observatoire à Monaco à une quinzaine de kilomètres du grand centre gravettien à statuettes féminines des Balzi Rossi (Cartailhac 1912 ; Onoratini et Da Silva 1978 ; Boule et Villeneuve 1927).

Dans la plupart des gisements mentionnés (Isturitz, Tarté, Lezia, la Tuto de Camalhot, Lespaux, Pataud, la Roque Saint-Christophe, Le Petit-Puyrousseau, Les Vachons, Laraux), la pointe des Vachons est associée à un niveau de Gravettien à burins de Noailles (Isturitz, niveau IV/F3 ; Tarté, niveau moyen et supérieur ; La Tuto de Camalhot, Lespaux, couche III, Pataud, couche 4 ; La Roque Saint-
Christophe, couche A ; Les Vachons, couche 4 ; Laraux, niveau 3). Dans certains sites comme Gargas et Brassempouy, les pointes des Vachons ne sont pas strictement associées au Gravettien à burins de Noailles bien que cette attribution soit très probable. L'ancienneté des fouilles expliquerait alors l'isolement des pièces. À Lezia, de véritables fouilles n'ont pas été possibles mais l'ensemble du matériel collecté est cohérent avec une attribution au Gravettien à burins de Noailles. Aucun vestige d'un autre faciès du Gravettien n'ayant été identifié, nous considérons l'association des pointes des Vachons au Gravettien à Noailles comme très probable. À l'abri des Roches (couche 3), certaines pointes à dos pourraient être des pointes des Vachons. Elles seraient alors associées à du Gravettien à élément tronqué, à burin du Raysse et peut-être à burin de Noailles. L'hypothèse d'un mélange peut cependant être envisagée. À Laussel, le matériel collecté lors des fouilles anciennes laisse entrevoir une importante occupation à burins de Noailles. Cette attribution pour les rares pointes des Vachons est donc possible. L'assemblage de La Faurélie est trop restreint et trop ubiquiste pour pouvoir être identifié précisément d'un point de vue chronoculturel. Le Roc de Gavaudun offre des pointes des Vachons associées au Gravettien à burins de Noailles mais l'homogénéité de l'assemblage doit être contrôlée. Enfin, les pointes de Pair-Non-Pair sont associées à du Gravettien sans burin de Noailles dont la détermination reste à entreprendre. Dans la grotte de l'Observatoire, les fouilles sont également anciennes et aucun faciès gravettien n'a été précisément identifié.

En définitive, sur les 17 premiers sites identifiés qui présenteraient des pointes des Vachons, 16 ont été fouillés anciennement. En France, seul l'abri Pataud possède une stratigraphie de référence pour l'étude de la variabilité interne des industries gravettiennes. Néanmoins, notre réévaluation de l'industrie lithique du Gravettien d'Isturitz à l'aide du tamisage des déblais tend à démontrer une homogénéité des séries anciennement collectées (Simonet 2009, 2010). À l'instar de Pataud, les pointes des Vachons seraient associées au Gravettien à burins de Noailles. Nous avons obtenu des conclusions similaires à Brassempouy où une seule tradition gravettienne semble représentée : le Gravettien à burins de Noailles (Simonet 2009, 2011). À l'avenir, une évaluation des séquences de Lespaux (Gironde), Laraux (Vienne) et des Vachons (Charente) ainsi que l'étude précise des pointes à dos du Flageolet I (Dordogne) apporteraient probablement de nouveaux indices. Enfin, un potentiel scientifique très important est fourni par la reprise des fouilles du Gravettien à burins de Noailles à Gargas (Hautes-Pyrénées) sous la direction de M. P. Foucher (Foucher et al. 2008) et par l'occupation gravettienne à burins de Noailles récemment découverte à Mareuil-sur-Cher (Loir-et-Cher) (Kildea et Lang 2011).

\section{4 - Conclusions : un nouveau fossile directeur?}

À l'heure actuelle, aucun argument ne permet d'affirmer que la pointe des Vachons est contemporaine du faciès gravettien à burin de Noailles car nous nous heurtons au problème de l'ancienneté des fouilles. D'un autre côté, 


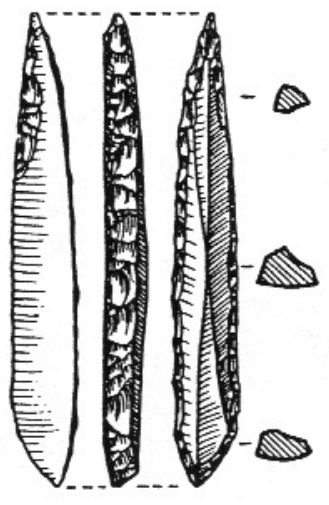

1

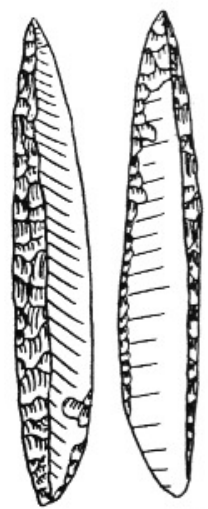

2

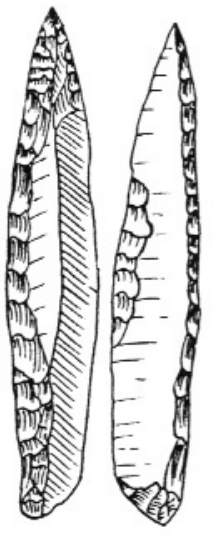

3 $\downarrow$

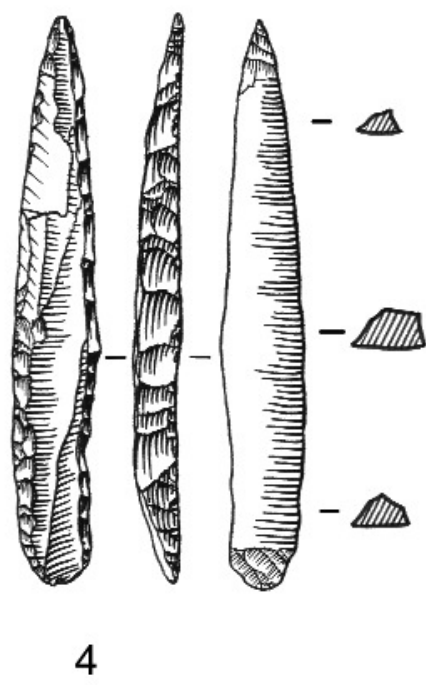

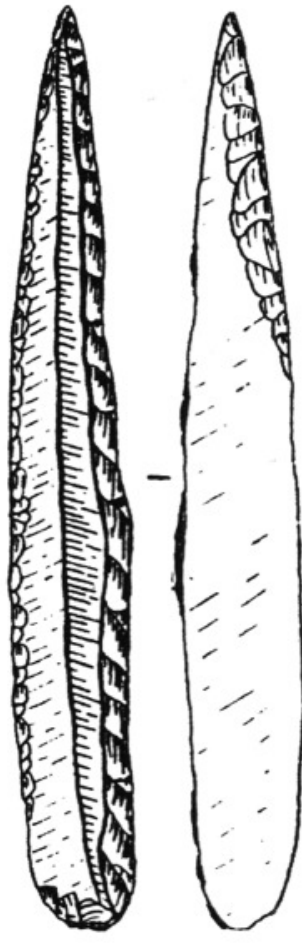

C.IIIIII)

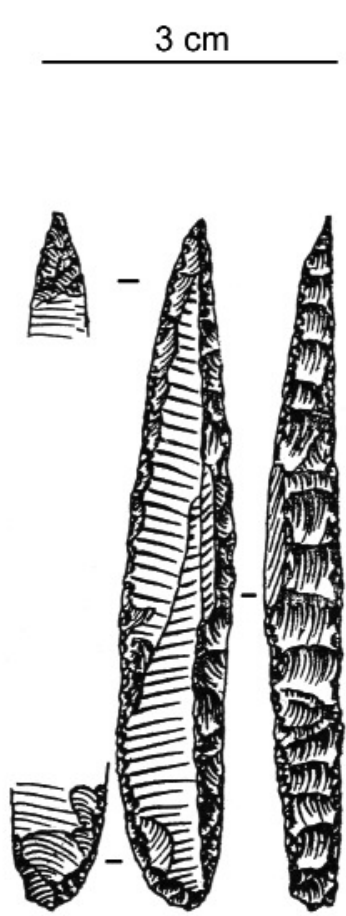

6

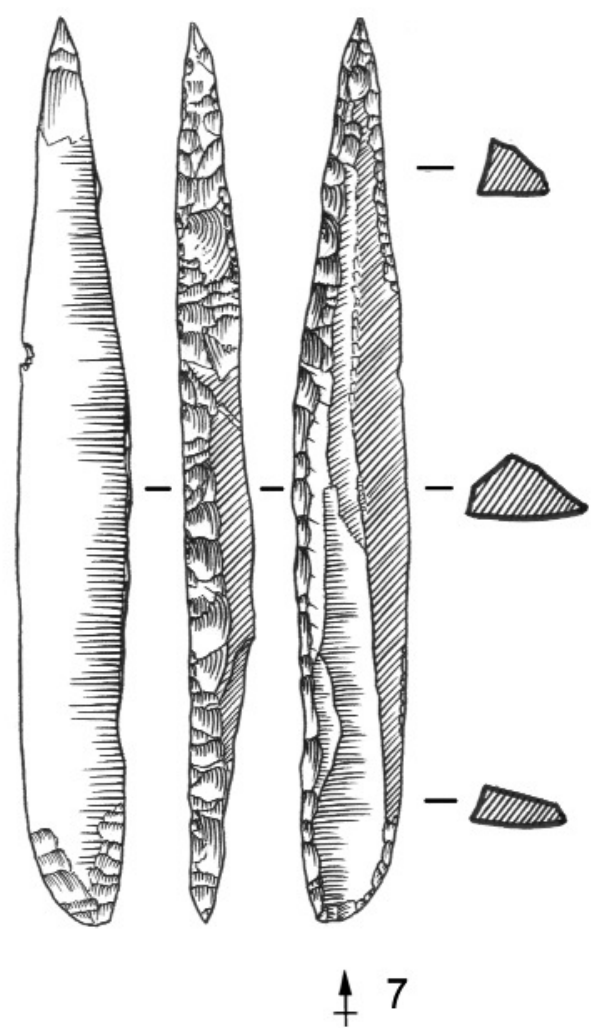

Figure 18 - Pointes des Vachons issues d'assemblages gravettiens français. $N^{\circ} 1$ : abri Pataud, niveau 4a, d'après Bricker 1995, fig. 30p. $N^{\circ} 2$ : la Faurélie, d'après Sonneville-Bordes 1960, fig. 123 - nos 21 et 22. $N^{\circ} 3$ : la Roque Saint-Christophe, couche A, d'après Sonneville-Bordes 1960, fig. $113-n^{\circ}$ 2.. $N^{\circ} 4$ : Laussel, dessin A. Simonet. $N^{\circ} 5$ : Laraux, niveau 3, d’après Pradel et Chollet, 1950, fig. 4 - $n^{\circ}$ 23. $N^{\circ} 6$ : abri Lespaux, couche III, d'après Cousté et Krtolitza1965, fig. 21. N 7 : Pair-Non-Pair, couche 6, dessin A. Simonet.

Figure 18 - Vachons points from French gravettian assemblages. $N^{\circ} 1$ : abri Pataud, level $4 a$, after Bricker 1995, fig. 30p. $N^{\circ} 2$ : la Faurélie, after Sonneville-Bordes 1960, fig. 123 - nos 21 and 22. № 3: la Roque Saint-Christophe, level A, after Sonneville-Bordes 1960, fig. $113-n^{\circ}$ 2. $N^{\circ}$ 4: Laussel, drawing A. Simonet. $N^{\circ}$ 5: Laraux, level 3, after Pradel and Chollet 1950, fig. $4-n^{\circ}$ 23. $N^{\circ}$ 6: abri Lespaux, level III, after Cousté and Krtolitza 1965, fig. 21. N 7: Pair-Non-Pair, level 6, drawing A. Simonet. 

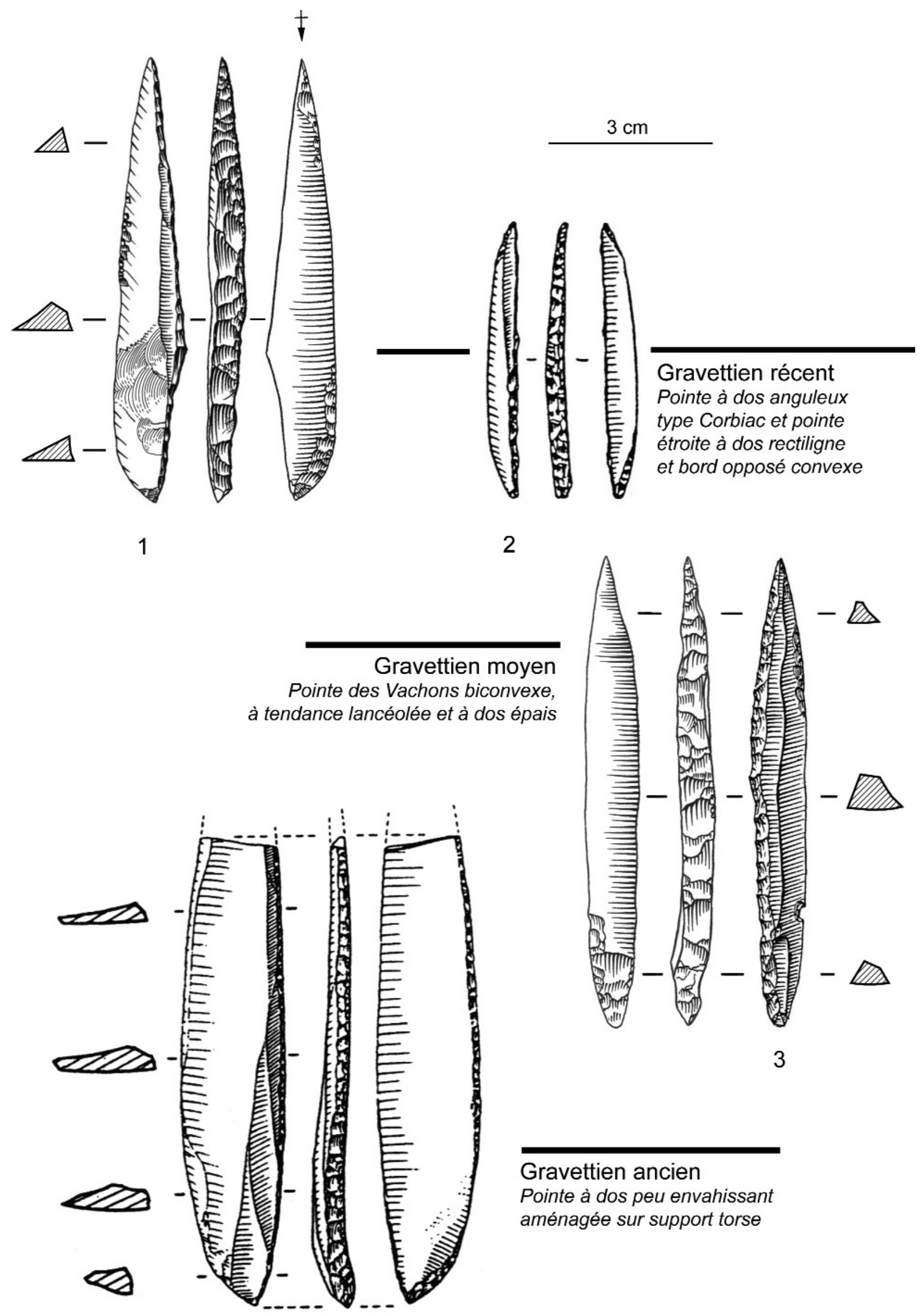

Gravettien ancien

Pointe à dos peu envahissant aménagée sur support torse

Figure 19 - Perspective de recherche : différents types de pointes à dos gravettiennes ? $N^{\circ} 1$ : Isturitz, niveau C, dessin A. Simonet. $N^{\circ} 2$ : abri Pataud, niveau 3, d'après Bricker dir. 1995, fig. 26D. $N^{\circ} 3$ : Isturitz, niveau IV, d'après Saint-Périer 1952, fig. $43-n^{\circ} 11$, modifié. $N^{\circ} 4$ : Pataud, niveau 5, d'après Bricker dir. 1995, fig. 54B.

Figure 19 - Research perspective: different types of gravettian backed points ? $N^{\circ} 1$ : Isturitz, level C, drawing A. Simonet. $N^{\circ} 2:$ abri Pataud, level 3, after Bricker dir. 1995, fig. 26D. $N^{\circ}$ 3: Isturitz, level IV, after Saint-Périer 1952, fig. $43-n^{\circ} 11$, modified. $N^{\circ} 4:$ Pataud, level 5, after Bricker dir. 1995, fig. 54B. 
aucun indice ne s'y oppose puisque les séries importantes de pointes des Vachons comme celles de Lespaux, d'Isturitz ou de Laraux ne proviennent pas d'assemblages attribués à un faciès ancien ou récent du Gravettien mais semblent bien associées à un faciès moyen à burins de Noailles. Si la probabilité que la pointe des Vachons représente un fossile directeur des phases moyennes du Gravettien est assez importante, une autre question plus délicate demeure : celle de la possibilité de l'existence d'un faciès du Gravettien moyen à pointes des Vachons, dissocié du faciès à Noailles. L'ancienne proposition de Cheynier selon laquelle il existerait un moment à pointes des Vachons couronnant le Gravettien à Noailles retrouverait ainsi toute sa pertinence (Cheynier 1965). En définitive, cette question de l'individualisation des pointes des Vachons recoupe celle des faciès du Gravettien qui sont encore très mal connus. Le découpage en faciès est d'ailleurs particulièrement sensible pour les phases moyennes du Gravettien (Rigaud 1982 ; Klaric 2003 ; Pottier 2005). Quoi qu'il en soit, la pointe des Vachons possède d'ores et déjà une forte valeur chronologique : elle succèderait aux pointes à dos plus marginal du Gravettien ancien confectionnées sur des supports légèrement torses en partie proximale (Pesesse 2008) et seraient remplacées dans le Gravettien récent du Sud-Ouest français par des pointes à dos très rectiligne comme dans le Gravettien récent de l'abri Pataud (Bricker dir. 1995), du Cirque de la Patrie (Klaric 2003) ou de Tercis (Thibault 1970 ; Simonet 2009) ou par des pointes à dos anguleux avec des bases aménagées par troncature oblique convexe comme dans le Gravettien récent de Corbiac (Kozlowski et Lenoir 1988) (fig. 19). II paraît d'ores et déjà évident que le concept de pointe à dos a évolué au cours du Gravettien et que la définition de la pointe des Vachons ne peut exister que par contraste avec celle de ces autres types de pointes dont l'étude reste à entreprendre. Par ailleurs, si l'utilisation de la retouche inverse rasante semble posséder une occurrence plus importante sur les pointes des Vachons (Bricker dir. 1995), elle pourrait néanmoins se retrouver sur d'autres types de pointes à dos et ne constituerait pas un critère d'identification diagnostique (fig. 19).

D'un point de vue géographique, la représentation dominante des pointes des Vachons au sein des gisements pyrénéens apporterait un indice supplémentaire dans une démarche de régionalisation. Le Gravettien des Pyrénées se démarquait déjà par l'omniprésence du burin de Noailles, l'importance des pièces esquillées, la présence de grattoirs et de burins sur bout de lame appointées ainsi que celle de lames retouchées et appointées (McCollough 1971; Clottes 1976 ; Bernaldo de Quirós 1982a, 1982b ; David 1985 ; Buisson et Delporte 1989 ; Ruiz Idarraga 1990 ; Esparza San Juan et Mújika Alustiza 1996 ; Foucher 2004). Tandis que le Gravettien à Noailles et à pointes des Vachons serait vite remplacé dans le Périgord, celui-ci pourrait avoir une fourchette chronologique plus large dans les Pyrénées.

Cette question du découpage chronologique et géographique selon la présence des pointes des Vachons peut être posée à plusieurs niveaux de lecture. Elle est pertinente à l'échelle du Gravettien moyen et du Gravettien récent du grand Sud-Ouest français. Mais l'intérêt d'individualiser ce type de pointe à dos prend un poids

particulier lorsque nous élargissons le champ de perception des groupes humains du Paléolithique supérieur d'Europe occidentale.

Phénomène très intéressant, notamment dans le cadre du débat sur la signification culturelle de la variabilité des industries lithiques et de la pertinence du découpage géochronologique, remarquons la perduration possible des pointes des Vachons dans des phases postérieures au Gravettien de l'est de la France et de l'Italie comme dans le Proto-Arénien et l'Epigravettien alors qu'elles seraient absentes des assemblages contemporains, solutréens et magdaléniens, français et espagnols (fig. 20). Au-delà d'une meilleure compréhension des sociétés gravettiennes, c'est peut-être à celle de plusieurs grandes sociétés du Paléolithique supérieur qu'une définition de plus en plus fine de l'unité, de la diversité et de la variabilité des pointes à dos pourra à l'avenir contribuer.

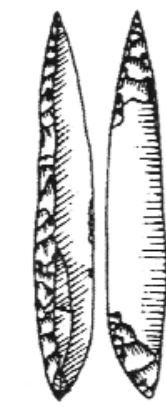

1

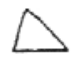

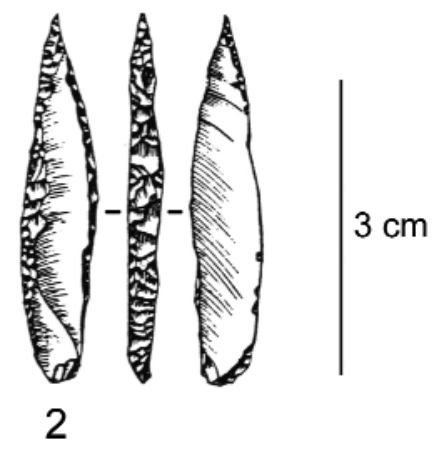

Figure 20 - Pointes des Vachons possibles provenant d'assemblages extra-gravettiens. $N^{\circ} 1$ : la Bouverie, couche 3 , Proto-Arénien, d'après Onoratini 1982. $N^{\circ} 2$ : la Font Pourquière, Tardigravettien ancien, d'après Livache 1976, fig. 2.

Figure 20 - Possible Vachons points from extra-gravettian assemblages. $N^{\circ}$ 1: la Bouverie, level 3, Proto-Arénien, after Onoratini 1982. $N^{\circ}$ 2: la Font Pourquière, Tardigravettien ancien, after Livache 1976, fig. 2.

\section{Remerciements}

Cet article correspond à une version adaptée d'un chapitre de notre thèse. II prend donc en compte les corrections transmises par certains membres du jury comme L. Klaric et P. Foucher que nous remercions vivement. Tous nos remerciements s'adressent à $P$. Périn, Directeur du Musée d'Archéologie Nationale et C. Schwab, conservatrice du Département Paléolithique pour nous avoir autorisé l'étude des séries gravettiennes des grottes d'Isturitz et de Brassempouy, J.-J. Cleyet-Merle, Conservateur en chef du Patrimoine du Musée National de Préhistoire et A. Morala pour nous avoir autorisé l'étude de la série gravettienne des Vachons, F. Hubert, Conservateur en chef du Musée d'Aquitaine à Bordeaux et V. Mistrot qui nous ont permis d'avoir accès aux collections de Laussel et Pair-Non-Pair dans les meilleures conditions, à P. Simon, Directeur du Musée d'Anthropologie préhistorique de Monaco pour 
nous avoir autorisé l'étude des collections de la grotte de l'Observatoire et des Balzi Rossi et à R. Nespoulet pour nous avoir autorisé l'étude des collections de l'abri Pataud. Nos remerciements vont aussi à J. Darricau, propriétaire de la grotte d'Isturitz et à C. Normand. Enfin, nous remercions F. Bon, A. Morala, J.P. Rigaud et P.-Y. Demars pour leur relecture et leurs corrections.

\section{Références bibliographiques}

BERNALDO DE QUIRÓS F. 1982a - Los inicios del Paleolítico superior cantábrico. Centro de Investigación y Museo de Altamira, Monografias n², Madrid, 347 p.

BERNALDO DE QUIRÓS F. 1982b - The early upper Palaeolithic in Cantabrian Spain (Asturias-Santander). In : Aurignacien et gravettien en Europe, Actes des réunions de la $10^{\mathrm{ème}}$ commission de I'U.I.S.P.P., fascicule II, ERAUL 13, Liège, p. 65-78.

BORDES F. 1965 - A propos de typologie. L'Anthropologie, 69, p. 369-377.

BORDES F. et LABROT J., 1967 - La stratigraphie du gisement de Roc de Combe (Lot) et ses implications. Bulletin de la Société Préhistorique Française, 64, $\mathrm{n}^{\circ} 1$, Études et Travaux, p. 15-28.

BOSSELIN B. et DJINDJIAN F. 1994a - La chronologie du Gravettien français, Préhistoire européenne, volume 6, p. 77-115.

BOSSELIN B. et DJINDJIAN F. 1994b - Périgordien et Gravettien : l'épilogue d'une contradiction, Préhistoire Européenne, volume 6, p. 117-131.

BOULE M., VILLENEUVE L. de 1927 - La grotte de l'Observatoire à Monaco. Paris, Masson. Archives de l'Institut de Paléontologie humaine, 1, 113 p. et 26 pl.

BOUYSSONIE J. 1939 - La grotte de Tarté. In : Mélanges de Préhistoire et d'Anthropologie offerts au Professeur Comte H. Bégouën. Toulouse : Édition du Muséum, Toulouse, p. 179-194, fig.

BOUYSSONIE J. 1948 - Le gisement aurignacien et périgordien des Vachons (Charente). L'Anthropologie, 52, p. 1-42, fig.

BOUYSSONIE J. et SONNEVILLE-BORDES D. 1956 L'abri $n^{\circ} 2$ des Vachons, gisement aurignacien et périgordien, commune de Voulgézac (Charente). Congrès Préhistorique de France, p. 1-39.

BREUIL H. et CHEYNIER A. 1958 - Les fouilles de Breuil et Cartailhac dans la grotte de Gargas en 1911 et 1913 . Bulletin de la Société méridionale de Spéléologie et de Préhistoire, V, 1954-1955, p. 341-382 (extrait du Bulletin de la Société d'Histoire Naturelle de Toulouse, 93).

BREUIL H. et CHEYNIER A. 1963 - La caverne de PairNon-Pair, Gironde. Fouilles de François Daleau. Documents d'Aquitaine (II), Publication de la Société archéologique de Bordeaux, $213 \mathrm{p}$.
BRICKER H. M. (dir.) 1995 - Le Paléolithique supérieur de l'Abri Pataud (Dordogne) : les fouilles de H. L. Movius Jr. ; suivi d'un inventaire analytique des sites aurignaciens et périgordiens de Dordogne. Paris : Maison des sciences de l'Homme, DAF, 50, 328 p.

BUISSON D., DELPORTE H. 1989 - Périgordien supérieur et Solutréen dans les Pyrénées françaises. In : J.-P. Mohen (éd.), Le Temps de la Préhistoire. Éditions de la Société préhistorique française, Archéologia, 1, p. 290-293.

CARTAILHAC E. 1912 - Les grottes de Grimaldi (BaousséRoussé). Tome II, fascicule 2 : Archéologie. Monaco, Imprimerie de Monaco, p. 213-324.

CÉLERIER G. 1967 - Le gisement périgordien supérieur des " Jambes ", commune de Périgueux (Dordogne). Bulletin de la Société Préhistorique Française, $64, n^{\circ} 1$, Études et Travaux, p. 53-68.

CHAUCHAT C. 1973 - La grotte Lezia à Sare. Bulletin du Musée Basque, p. 155-166.

CHEYNIER A. 1965 - Comment vivait l'homme des cavernes à l'âge du renne. Paris : édition du Scorpion, $227 \mathrm{p}$, fig.

CLOTTES J. 1976 - Les civilisations du Paléolithique supérieur dans les Pyrénées. In : H. de Lumley (dir.), La Préhistoire française. Paris, CNRS, 2, p. 1212-1231.

COIFFARD J. 1914 - Station des Vachons, commune de Voulgézac (Charente). Comptes Rendus de l'Association française pour l'avancement des sciences, Congrès du Havre, p. 623-627.

COIFFARD J. 1922 - Station des Vachons, abri 2. Comptes Rendus de l'Association française pour l'avancement des sciences, Congrès de Montpellier, p. 493-495.

COIFFARD J. 1937 - L'Aurignacien en Charente, (..., station des Vachons...). Bulletins et mémoires de la Société Archéologique et Historique de la Charente, p. 113-128.

COUSTÉ R. et KRTOLITZA K. 1965 - L'Abri Lespaux (commune de Saint-Quentin-de-Baron) et la question du Périgordien en Gironde. Revue Historique et Archéologique du Libournais, 33, n 116, p. 47-54.

DAVID N.C. 1985 - Excavations of the abri Pataud, Les Eyzies (Dordogne): The Noaillien (level 4) assemblages and the Noaillien culture in Western Europe. Peabody Museum, Harvard University, American School of Prehistoric Research, 37, $355 \mathrm{p}$.

DELPORTE H. 1983 - L'organisation du Périgordien supérieur en France et ses rapports avec le Périgordien d'Europe occidentale. Etudes et recherches Archéologiques de l'Université de Liège, ERAUL n 13, p. 83-106.

DELPORTE H. (dir.) 1984 - Le grand abri de la Ferrassie : Fouilles 1968-1973. Paris : Ed. du Laboratoire de Paléontologie Humaine et de Préhistoire, Etudes Quaternaires, mémoire $\mathrm{n}^{\circ} 7,277 \mathrm{p}$. 
ESPARZA SAN JUAN X., MÚJIKA ALUSTIZA J.A. 1996 - El Perigordiense superior en el Pais Vasco. In : H. Delporte et J. Clottes (dir.), Pyrénées Préhistoriques - Arts et Sociétés, actes $d u 118^{\circ}$ congrès national des sociétés historiques et scientifiques, Pau, 1993. Editions du CTHS, p. 61-71, fig.

FISHER A., VEMMING H. P., RASMUSSEN P. 1984 - Macro and microwear traces on lithic projectile points : experimental results and prehistoric examples. Journal of Danish Archeology, 3, p. 19-46.

FOUCHER P. 2004 - Les industries lithiques du complexe gravettien-Solutréen dans les Pyrénées. Techno-typologie et circulation des matières siliceuses de part et d'autre de l'axe Pyrénées-Cantabres. Thèse de doctorat de l'université de Toulouse-Le Mirail, 2 tomes, 334 p. et 245 fig.

FOUCHER P., SAN JUAN-FOUCHER C., FERRIER C., COUCHOUD I., VERCOUTÈRE C. 2008 - La grotte de Gargas (Aventignan, Hautes-Pyrénées) : nouvelles perspectives de recherche et premiers résultats sur les occupations gravettiennes, in Jaubert J., Bordes J.-G., Ortega I. (dir.), Les sociétés paléolithiques d'un grand Sud-Ouest Nouveaux gisements, nouvelles méthodes, nouveaux résultats. Actes des journées de la Société préhistorique française et de l'Université de Bordeaux I, 2006, Société Préhistorique Française (« Mémoire 47 »), p. 301-324.

GOUTAS N. 2004 - Caractérisation et évolution du Gravettien en France par l'approche techno-économique des industries en matière dure animale. Thèse de doctorat, Université de Paris I-Panthéon-Sorbonne, $680 \mathrm{p}$.

HEINZELIN de BRAUCOURT J. de 1962 - Manuel de typologie des industries lithiques. Bruxelles, 74 p., pl.

KILDEA F. et LANG L. 2011 - Les occupations du Gravettien moyen à burins de Noailles et du Gravettien récent du site de " La Croix de Bagneux " à Mareuil-sur-Cher (Loir-etCher), in D. Pesesse, N. Goutas, L. Klaric et P. Guillermin dir., À la recherche des identités gravettiennes : actualités, questionnements et perspectives, Actes de la table ronde d'Aix-en-Provence, 2008, Société Préhistorique Française (« Mémoire » 52), p. 273-289.

KLARIC L. 2003 - L'unité technique des industries à burins du Raysse dans leur contexte diachronique. Réflexions sur la diversité culturelle au gravettien à partir des données de la Picardie, d'Arcy-sur-Cure, de Brassempouy et du Cirque de la Patrie. Thèse de doctorat, Université de Paris I Panthéon-Sorbonne, $426 \mathrm{p}$.

KLARIC L., AUBRY T., WALTER B. 2002 - Un nouveau type d'armature en contexte gravettien et son mode de production sur les burins du Raysse (la Picardie, commune de Preuilly-sur-Claise). Bulletin de la Société Préhistorique Française, 99, n 4, p. 751-764.

KOZLOWSKI J. K. et LENOIR M. 1988 - Analyse des pointes à dos des gisements périgordiens de l'Aquitaine, Uniwersytet Jagiellonski, Cracovie.

KRTOLITZA Y. et LENOIR M. 1998 - Un gisement du Gravettien à burins de Noailles en Gironde : l'abri Lespaux à Saint Quentin de Baron. Revue archéologique de Bordeaux, 89, p. 47-68.

LALANNE G. et BOUYSSONIE J. 1946 - Le gisement paléolithique de Laussel, fouilles du Docteur Lalanne. L'Anthropologie, L, p. 1-164, fig.

LIVACHE M. 1976 - Les civilisations du Paléolithique supérieur en Haute Provence et dans le Vaucluse. In : H. de Lumley (Dir.), Les civilisations paléolithiques et mésolithiques de la France, Tome II. Paris : Éditions du Centre National de la Recherche Scientifique, p. 1157-1163.

LUCAS G. 2000 - Les industries lithiques du Flageolet I (Dordogne) : approche économique, technologique, fonctionnelle et analyse spatiale, Thèse de Doctorat de Préhistoire et de Géologie du Quaternaire de I'Université de Bordeaux I, vol. I : texte 307 p., vol. II : illustrations, 307 ill. et $49 \mathrm{pl}$.

McCOLLOUGH M.C. 1971 - Perigordian facies in the Upper Palaeolithic of Cantabria. Ph. D. Thesis, University of Pennsylvania, Michigan, 547 p.

MONMEJEAN E., BORDES F., SONNEVILLE-BORDES D. de 1964 - Le périgordien supérieur à burins de Noailles du Roc-de-Gavaudun (Lot-et-Garonne). L'Anthropologie, 68, 3-4, p. 253-316, fig., tabl.

O'FARRELL M. 1996 - Approche technologique et fonctionnelle des pointes de la Gravette : une analyse archéologique et expérimentale appliquée à la collection de Corbiac. Mémoire du DEA d'anthropologie option préhistoire, Université de Bordeaux I, 97 p.

O'FARRELL M. 2004 - Les pointes de La Gravette de Corbiac (Dordogne) et considérations sur la chasse au Paléolithique supérieur ancien. Approches fonctionnelles en Préhistoire, $X X V^{e}$ Congrès Préhistorique de France, Nanterre 24-26 novembre 2000, p. 121-138.

ONORATINI G. 1982 - Préhistoire, Sédiments, Climats du Würm III à l'Holocène dans le Sud-Est de la France. Travaux E.R. 46, Université d'Aix-Marseille III, Mémoire $\mathrm{n}^{\circ} 1,2$ t., 383 p. et $401 \mathrm{p}$.

ONORATINI G., DA SILVA J. 1978 - La grotte des Enfants à Grimaldi, les foyers supérieurs, in Bulletin du Musée d'Anthropologie et de Préhistoire de Monaco, 22, p. 31-71.

PASSEMARD E. 1944 - La caverne d'Isturitz en Pays Basque. Préhistoire, 9. Paris : Presses Universitaires de France, 95 p., fig., pl.

PESESSE D. 2006 - La « pointe à dos alternes », un nouveau fossile directeur du Gravettien ?, Bulletin de la Société Préhistorique Française, tome 103, n 3, p. 465-478.

PESESSE D. 2008 - Les premières sociétés gravettiennes : analyse comparée des systèmes lithiques de la fin de l'Aurignacien aux débuts du Gravettien, Thèse de doctorat de l'Université d'Aix Marseille 1, 2 vol., 276 p. et 179 f. de pl.

PIETTE E., DE LAPORTERIE J. 1898 - Etudes d'ethnographie préhistorique. V, Fouilles à Brassempouy en 1897. L'Anthropologie, IX, n 5, p. 531-555. 
POTTIER C. 2005 - Le Gravettien moyen de l'abri Pataud (Dordogne, France), le niveau 4 et l'éboulis 3/4 : étude technologique et typologique de l'industrie lithique. Thèse de doctorat, Paris, Muséum national d'Histoire Naturelle, $393 \mathrm{p}$.

PRADEL L. 1965 - L'abri aurignacien et périgordien des Roches, commune de Pouligny-Saint-Pierre (Indre). L'Anthropologie, 69, n 3-4, p. 219-236.

PRADEL L. 1979 - L'abri périgordien de Laraux, commune de Lussac-Les-Châteaux (Vienne). Nouvelles constatations et datations par le radio-carbone. L'Anthropologie, tome 83, $n^{\circ}$ 3, p. 439-554.

PRADEL L. et CHOLLET A. 1950 - L'abri périgordien de Laraux, commune de Lussac-les-Châteaux (Vienne). L'Anthropologie, 54, p. 214-227, fig.

RIGAUD J.-P. 1982 - Le Paléolithique en Périgord : les données du Sud-Ouest sarladais et leurs implications, Thèse de doctorat, Bordeaux I, 2 tomes, 493 p., 242 fig., 17 tabl.

RUIZ IDARRAGA R. 1990 - El complejo AuriñacoPerigordiense en el País Vasco. Munibe, 42, p. 23-32, fig.

SAINT-PÉRIER R. de 1952 - La grotte d'Isturitz. III : les Solutréens, les Aurignaciens et les Moustériens. Archives de l'Institut de Paléontologie humaine, mémoire $\mathrm{n}^{\circ} 25$. Paris : Masson, 264 p., fig., pl.

SIMONET A. 2009 - Les gravettiens des Pyrénées. Des armes aux sociétés. Thèse de doctorat, Université de Toulouse II - Le Mirail, 391 p.
SIMONET A. 2010 - Typologie des armatures lithiques gravettiennes de la grotte d'Isturitz (Pyrénées-Atlantiques, France), Oxford, Archaeopress, BAR International Series, 2156, $133 \mathrm{p}$.

SIMONET A. 2011 - Le Gravettien du Chantier I de Brassempouy (Landes, France). In : D. Pesesse, N. Goutas, L. Klaric et P. Guillermin dir., À la recherche des identités gravettiennes : actualités, questionnements et perspectives, Actes de la table ronde d'Aix-en-Provence, 2008, Société Préhistorique Française (« Mémoire » 52), p. 57-66.

SONNEVILLE-BORDES D. de 1960 - Le Paléolithique supérieur en Périgord. Bordeaux : Delmas, Bordeaux, 558 p.

SONNEVILLE-BORDES D. de 2002 - Les industries du Roc-de-Combe (Lot). Périgordien et Aurignacien. Préhistoire du Sud-Ouest, n 9, fasc. 2, p. 121-161.

SONNEVILLE-BORDES D. de et PERROT J. 1956 - Lexique typologique du Paléolithique Supérieur. Bulletin de la Société Préhistorique française, 53, fascicule 9, p. 547-560, fig.

SORIANO S. 1998 - Les Microgravettes du Périgordien de Rabier à Lanquais (Dordogne). Analyse technologique fonctionnelle. Gallia préhistoire, 41, p. 75-94, fig., tabl.

THIBAULT C. 1970 - Recherches sur les terrains quaternaires du Bassin de l'Adour. Thèse de Doctorat, Université de Bordeaux I, 4 vol., 840 p., 171 fig. et LXVIII pl.

VEZIAN J. et J. 1966 - Les gisements de la grotte de SaintJean-de-Verges (Ariège). Gallia Préhistoire, IX, fascicule 1, p. 93-130, fig. 
